\title{
Remote Sensing Based Modeling of Water and Heat Regimes in a Vast Agricultural Region
}

\author{
A. Gelfan ${ }^{1}$, E. Muzylev ${ }^{1}$, A. Uspensky², Z. Startseva ${ }^{1}$ and P. Romanov ${ }^{3}$ \\ 1Water Problem Institute of Russian Academy of Sciences, Moscow \\ ${ }^{2}$ State Research Center of Space Hydrometeorology Planeta, Moscow \\ ${ }^{3}$ City College of City University of New York, New York, NY \\ 1,2Russia \\ ${ }^{3}$ USA
}

\section{Introduction}

In many parts of the world, solution of the problem of water security is closely associated with possibility and predictability of access to soil water which accounts, globally, for approximately $60 \%$ of total rainfall. Soil water, so-called "green water", is fundamentally significant for maintaining sustainability of ecosystems and providing water for agriculture (in average, agriculture demands about $70 \%$ of global water use, and over $90 \%$ in some regions (Global Water Security, 2010). In addition, changes in the store of soil water due to evapotranspiration, infiltration of surface water and other water cycle processes strongly affect land-atmosphere interactions on intraseasonal to interannual timescales (Yang, 2004) and understanding physical mechanisms of these processes is central for effective modeling mesoscale atmospheric circulation.

Taking into account a vital role of "green water" both for ecosystems and agriculture, there is a need for physically based models allowing to describe land-surface processes in their interaction with atmosphere and to predict soil water availability under changing environment and climate. Processes of mass and energy exchange at the land surface, linking the atmosphere and soil water are of interest to several geophysical disciplines; particularly, the possibility of developing adequate models of these processes was studied intensively by hydrological and meteorological communities for a few decades. Recently, a huge contribution to our understanding these processes has been made by remote sensing community. Combination of these efforts results in intensive developing so called landsurface models (LSMs), considering as a key tool to predict successfully the likely future states of the terrestrial systems under anthropogenic pressure and climate change. There are a lot of reviews providing a detailed and comprehensive discussion of LSMs (e.g. Sellers et al., 1997; Pitman, 2003; Overgaard et al., 2006). Most of them are concentrated on the development of LSMs designed for use in weather and climate models. Below a review of LSMs will be done with emphasis on their availability to capture processes controlling soil water dynamics, and primarly, evapotranspiration. Additionally, focus will be on utilization of remotely sensed data in LSMs. 
According to Sellers et al. (1997), the LSMs could be broadly divided onto three generations distinguishing largely on the level of complexity of the evapotranspiration process description. The first generation, developed in the late 1960s and 1970s, used simple bulk aerodynamic transfer formulations. Land surface considers as homogeneous one in the firstgeneration LSMs and spatially uniform surface parameters (water-holding capacity, albedo, roughness length etc.) are used, i.e. these models do not discriminate soil evaporation and transpiration. Examples are the "bucket" model by Manabe (1969) (probably, the earliest first-generation LSM) and more recent TOPUP model by Schultz et al. (1998), PROMET model by Mauser \& Schädlich (1998). Use of the single value of the aerodynamic resistance regardless of the surface type is one of the common simplifications and major conceptual limitations of the first-generation LSMs (Pitman, 2003). Another one is that these models include a single soil layer for soil moisture and temperature simulations. According to the findings of the Project for the Intercomparison of Landsurface Parameterisation Schemes (PILPS; Henderson-Sellers et al., 1995), soil moisture dynamics simulated by the firstgeneration LSMs can not be often reproduced adequately by these models because of aforementioned conceptual limitations.

The second generation of the LSMs, developed in the early 1980s, explicitly represented, in contrast to the first-generation models, the influence of vegetation on the interaction between land surface and atmosphere. Taking into account difference between soil and vegetation provided an opportunity to begin integrating satellite data into LSMs (Pitman, 2003). Also, these models improve soil moisture representation replacing the simple conceptual scheme of Manabe (1969) by more sophisticated parametrizations (particularly, the vertically distributed Richards equation is often used). Such a new direction in land surface modeling took roots from a pioneering work of Deardorff (1978) developed a model for simulating soil moisture and heat transfer in two layers and vegetation as a single layer controlling heat balance on a land surface, as well as from the works of Dickinson (1986) and Sellers et al. (1986) developed the Biosphere Atmosphere Transfer Scheme (BATS) and Simple Biosphere Model (SiB) based on the ideas of Deardorff (1978). During the subsequent decades, a huge number of the second-generation LSMs have been developed; examples include SVAT (Kuchment \& Startseva, 1991), VIC (Wood et al., 1992), BASE (Desborough \& Pitman, 1998), CLM (Dai et al., 2002), SWAP (Gusev \& Nasonova, 2002), LaD (Milly \& Shmakin, 2002).

One of the principal advantages of the second-generation LSMs is their ability to consider snow processes affecting a major part of terrestrial water balance in cold regions. Snow submodels of different vertical discretization have been implemented in LSMs and an intensive work on their evaluation and intercomparison (e.g. the recent SnowMIP2 Project (Rutter et al., 2009)) has been made. Additionally, some LSMs include parametrization of hydrothermal processes in a frozen soil (Wood et al., 1992; Gusev \& Nasonova, 2002 among others) but an adequate description of these processes strongly affected soil moisture content before vegetation season still remains problematic (Pitman, 2003).

A step forward of the third-generation LSMs is in explicit description of a canopy physiology including biophysical mechanisms of stomatal conductance, photosynthesis, plant growth, etc. This ability opens up new opportunities not only to improve reproduction of evapotranspiration but, importantly, to address carbon exchange by plant. Description of the other land surface processes (soil moisture and temperature dynamics, snow processes, 
etc.) is similar to one utilized in the second-generation LSMs. One of the first LSMs of third generation were developed by Collatz et al. (1991) and Sellers et al. (1992), some recent examples representing improvements of the aforementioned second-generation LSMs include modifications of the SVAT-model (Kuchment et al., 2006), the CLM-model (Oleson et al., 2008), the SiBcrop model (Lokupitiya et al., 2009).

One of the major concerns restricting availability of LSMs, particularly on a regional scale, is the issue of spatial heterogeneity of land surface characteristics (soil, vegetation, topography) required for assigning the model parameters. Regional (mesoscale) heterogeneity is not captured by the existing ground-based observational network that leads to an excessive aggregation of the parameters and, as a rule, to decrease in accuracy of reproducing spatial distribution of the desired processes. Significant improvement of performance of LSMs can be reached by assimilation of information that is additional to the ground observations, first of all, information on land surface provided by satellite remote sensing. Remote sensing allows substituting the missed ground observations by measurements of the incoming and outgoing land surface radiation fluxes conversed into physical distributed parameters. No exaggeration to say that spatial data on land surface derived from remote sensing is the only source of the distributed parameters for LSMs at regional scale. Additionally, these data can be used for model evaluation purposes. Applicability of satellite remote sensing for improvement of the land surface modeling is reviewed, e.g. by Overgaard et al. (2006), including results of a number of field experiments (FIFE, HAPEX, KUREX and others). However, in spite of the fact that quantity and quality of satellite products have largely increased for the last decade and they have recognized as a potentially valuable source of distributed information, the majority of satellite products still needs considerable improvement and applicability of these products, even being improved, should be verified both for the specific region and for the used LSM.

This paper has three major objectives. First, the existing satellite-derived data of land surface and snow cover characteristics will be overviewed in brief and the specific developed technologies of the satellite data thematic processing will be presented for the study region located within the agricultural Black Earth area of the European Russia. Secondly, structure of the physically based distributed Remote Sensing Based Land Surface Model (RSBLSM) developed for simulation of vertical water-and-heat transfer in vegetation, unfrozen and frozen soil, snow cover will be described and the results of its testing against the available ground-based observations will be shown. Finally, the results of utilizing satellite-derived land surface and snow characteristics as the parameters and input variables of RSBLSM, as well as for the model evaluation, will be demonstrated and discussed.

\section{Case study}

The case study has been carried out for agricultural Black Earth region of the European Russia of 227,300 km² located in the steppe-forest physiographic zone (Fig. 1)

Relief of the region is low middle-hilly plain dissected by broad river valleys, ravines and gullies. Dominant slopes are $\sim 1-4^{\circ}$. Absolute elevation marks of surface in the region are in the range of $150-260 \mathrm{~m}$. Annual net radiation is $27-32 \mathrm{kcal} / \mathrm{cm}^{2}$, and the sum of incoming solar radiation during the summer months is $41-44 \mathrm{kcal} / \mathrm{cm}^{2}$. Annual precipitation is 519 
$\mathrm{mm}$, over $40 \%$ of which falls as snow. Snow water equivalent significantly varies over the area. At the northern part of the region snow cover deceases in the middle of April, southern parts are snow-free in March. Maximum rainfall $(60-70 \mathrm{~mm})$ falls as a rule in July. Ground water level lies at the depth of 15-30 $\mathrm{m}$ between rivers and of 3-5 $\mathrm{m}$ in river valleys.

Soils are mainly chernozem (podzolized, leached and typical), small part of the territory is occupied by floodplain meadow and gray soil. In texture, soils mostly relate to the loam. Sandy loam and sand are found rarer. In the north-western part of the region gray foreststeppe soils with patches of degraded chernozem are located. When moving to the south gray soils give place to leached chernozem often occurring in combination with powerful chernozem. The southeastern part of the region is occupied by ordinary chernozem. Most of the region territory is under cultivation, the natural vegetation is preserved mainly in river valleys and on slopes of gullies and ravines. Plough-lands compose the most part of the region $(78 \%)$, forests occupy about $5 \%$; pastures take up about $16 \%$; urbanized lands occupy less than $1 \%$. The main crops are cereals (spring wheat and barley, winter wheat, less corn, buckwheat and rye) as well as sugar beets, potatoes and forage grasses. Ratio of crops in different households differs substantially. Region-averaged grain wedge is about $60 \%$ of all plough-lands. In the region there are 48 agricultural meteorological stations at which observations on meteorological characteristics and soil moisture under different crops, as well as snow cover characteristics are conducted. At several of them measurements of the evaporation pans are also made.

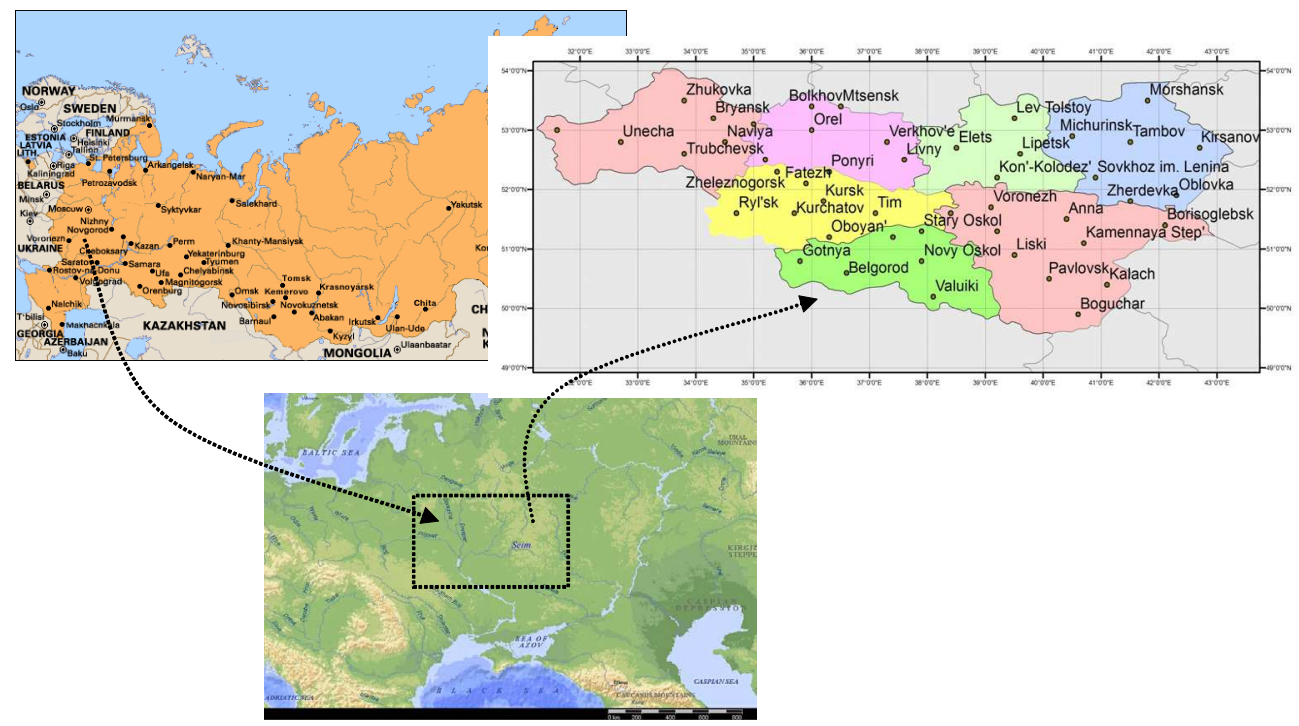

Fig. 1. Study region (points at the right upper map represent location of meteorological stations)

To assign the model parameters, most of which are the measured soil, vegetation and snow cover characteristics as well as to calibrate and validate the model the data have been attracted of above observations at agricultural meteorological stations for 21 years from 1971 to 2010 . 


\section{Remote sensing of agricultural regions: products and algorithms of data processing}

\subsection{Remote sensing of land surface and vegetation characteristics}

This section contains a brief overview of satellite instruments and methods for remote sensing of various land surface parameters, valuable in particular for hydrological applications. During the past decades, a series of sensors have been developed and launched, such as the Advanced Very High Resolution Radiometer (AVHRR) and the MODerate resolution Imaging Spectroradiometer (MODIS), which are respectively onboard the polar-orbiting satellites NOAA and NASA EOS Terra and Aqua. The AVHRR instrument has 6 VIS and IR channels with spatial resolution of $1 \mathrm{~km}$ (NOAA KLM Users Guide, 2005) that are informative with respect to different land surface and vegetation parameters. The MODIS instrument has 36 channels in VIS and IR (Justice et al., 1998) with 1 $\mathrm{km}$ spatial resolution, which provides information on even more geophysical parameters of land surface, vegetation, atmosphere, etc. In recent years new geostationary satellites have been developed, such as European Meteosat Second Generation (MSG), i.e. Meteosat-8 and 9. Meteosat main payload is the optical imaging radiometer, the so called Spinning Enhanced Visible and Infrared Imager (SEVIRI). SEVIRI has 12 spectral channels from VIS to IR (Schmetz et al., 2002). It has channels similar to AVHRR, and the benefit is that SEVIRI provides measurements of the Earth-disc every 15 minutes comparing to the coverage of the polar-orbiting satellites ( 2 times a day for the same territory).

Among the above mentioned geophysical parameters we will focus on: land surface temperature (LST or $T_{l s}$ ), air foliage temperature $\left(T_{a}\right)$, emissivity $(E)$, as well as normalized difference vegetation index $(N D V I)$, vegetation cover fraction $(B)$ and leaf area index (LAI). LST is one of the important geophysical parameters. Together with the land surface spectral emissivity ( $L S E$ ) the LST affect the heat and water transport between the surface and the atmosphere. There is a strong need in the remote sensing LST, since the conventional surface temperature observations are rather sparse (in space and time).

The possibilities of extracting LST and LSE information from thermal IR multichannel measurements in the "atmospheric window" spectral range (3.7-4.0, 10.5-12.5 $\mu \mathrm{m}$ ) has been the subject of numerous investigations during last 20 years, see (Becker \& Li, 1995).

Because of the land surface heterogeneity, the satellite measurements usually come from mixed pixels. At satellite pixel scale, LSE refers to the area-weighted and channel-averaged emissivity $(E)$ and $L S T$ refers to the radiometric surface temperature corresponding to the Field Of View (FOV) of a radiometer (Becker \& Li, 1995).

\subsubsection{AVHRR- and MODIS-based remote sensing products}

The methods have been developed and tested for AVHRR/NOAA data processing (Muzylev et al, 2002, 2005) that provide the retrieval of two types of LST (efficient radiation temperature $T_{\text {s.eff }}$ and land skin temperature $T_{g}$ ) and emissivity $E$ as well as the derivation of airvegetation temperature $T_{a}$ and three vegetation characteristics, namely, vegetation index $N D V I$, fraction $B$ and leaf area index $L A I$. The algorithms for AVHRR-based estimation of $T_{\text {s.eff }}, T_{g}, T_{a}$ utilize cloud-free measurements in the split window channels 4 and 5 and linear statistical regression similar to well-known split window technique (Becker et al., 1995; PUM 
LST, 2008; Wan et al., 1996). The values of emissivity $E_{4}$ and $E_{5}$ are specified a priori using one of alternate approaches. The required ancillary information is extracted from the classification-based emissivity model (Snyder et al., 1998) as well as from the empirical relationships between the emissivity and/or NDVI / B, see (Muzylev et al., 2002, 2005). To estimate $L A I$, the empirical relationships between $L A I$ and NDVI (established for different land covers) have been applied (see Section 5.1, formulas (27) and (28)).

The threshold technique of cloud detection in the AVHRR FOV has been used that has allowed increasing the reliability of cloud-free fragment detection (Volkova \& Uspenskii, 2007). The developed software package has been applied for AVHRR/NOAA cloud-free data thematic processing to generate named remote sensing products and cloud/precipitation parameters for various dates of the 1999-2010 vegetation periods. The error statistics of $T_{a}, T_{s g}$ and $T_{\text {s.eff }}$ derivation has been investigated for various samples using comparison with synchronous collocated in-situ measurements that has given rootmean square (RMS) errors in the range of $1.5-2.0,3.5-4.5$, and $2.5-3.5^{\circ} \mathrm{C}$ respectively (Muzylev et al., 2005, 2006, 2010). The archive of synchronous AVHRR/NOAA measurements, remote sounding data, and in-situ hydro-meteorological observations has been compiled for the study area and its separate parts for 1999-2010 vegetation seasons.

The dataset of MODIS-based remote sensing products has also been compiled on the base of special technology using LP DAAC web-site https://lpdaac.usgs.gov, that includes estimates of land surface temperature (LST) $T_{l s}, E, N D V I, L A I$ for the region of interest and 2003-2010 vegetation seasons. Two types of MODIS-based $T_{l s}$ and $E$ estimates have been extracted (for separate dates of the named time period): LST/E Daily L3 product (MOD11B1) with spatial resolution $\sim 4.8 \mathrm{~km}$ and LST/E 5-Min L2 product (MOD11_L2) with spatial resolution $\sim 1 \mathrm{~km}$. The verification of $T_{l s}$ estimates has been performed by the comparison against analogous and collocated AVHRR-based ones (Muzylev et al, 2010).

\subsubsection{SEVIRI-based land surface and land air surface temperature estimates}

In the recent years there were a lot of studies on LST derivations from SEVIRI/MSG data, see (PUM LST, 2008; Solovjev et al., 2009, 2010). In the State Research Center of Space Hydrometeorology "Planeta" (Moscow, Russia) the new methodology has been developed for the derivation of LST and LSE from cloud-free brightness temperatures measured in the SEVIRI channels $9(10.8 \mu \mathrm{m})$ and $10(12.0 \mu \mathrm{m})$ at three different times based on combination of two well-known techniques, i.e. split-window method (Wan et al., 1996) and two temperature method, see (Faysash et al., 2000) with additional hypothesis that the emissivity values $E_{9}$ and $E_{10}$ remain constant during the time interval between the first and the last image cycles used. The detailed description of the proposed technique can be found in (Uspensky et al., 2009; Solovjev et al., 2010). It is important to mention that unlike the technique from (PUM LST, 2008), this method does not require the accurate knowledge of emissivity $(E)$ in the split-window channels.

The method described has been used for the period of 2009-2011 to produce LST estimates over Europe and, in particular, for Black Earth zone of Russia. An example image of this LST mapping is presented in Fig. 2.

The comparison with synchronous and collocated LST products from Satellite Application Facility on Land Surface Analysis, SAF LSA (Lisbon, Portugal) (PUM LST, 2008) has been 


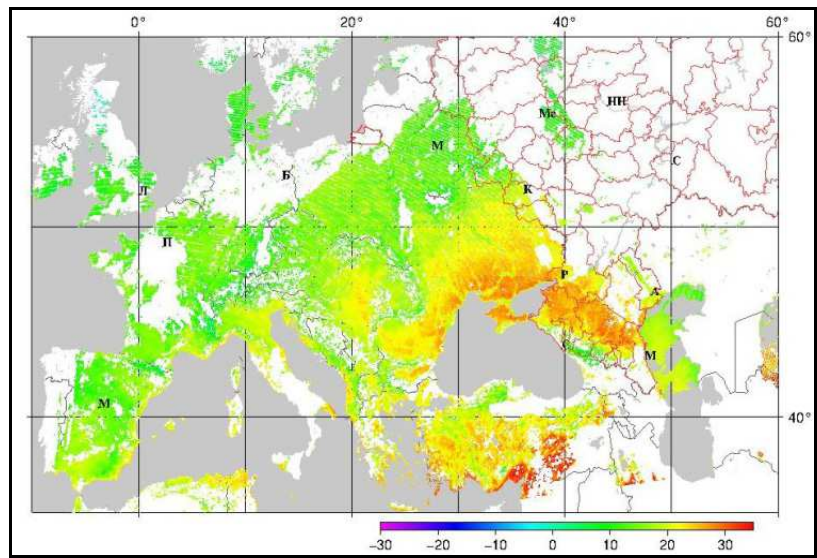

Fig. 2. LST map, 27.09.2011, 07:00 UTC

performed to validate the results over the central Europe. Good level of correlation has been reached, which could be treated as indirect proof of the method's efficiency. RMS deviation between the above mentioned LST estimates is in the range of $0.9-3.0^{\circ} \mathrm{C}$. The upper limit could be shifted down to $2.4^{\circ} \mathrm{C}$ by subtracting systematic biases.

An additional validation has been performed through the inter-comparison with MODISbased LST for the study region, see Fig. 3.
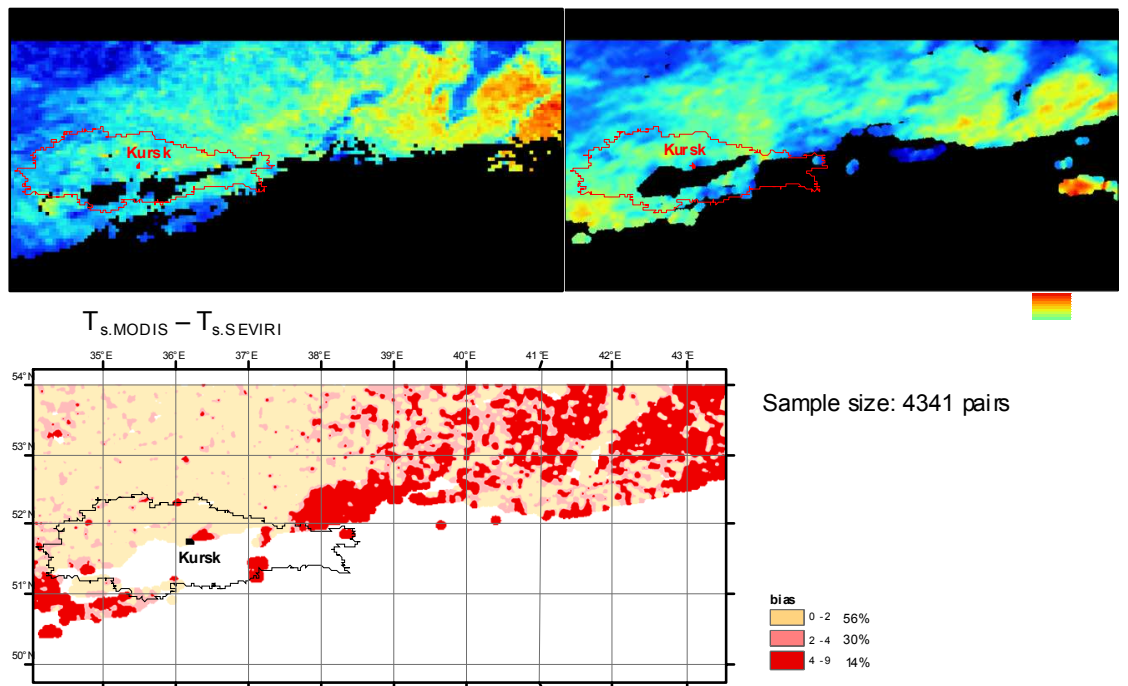

Fig. 3 Inter-comparison results for MODIS- and SEVIRI-based LST estimates

It is obvious that both LST maps are similar to each other. The discrepancy is rather small $\left(0.0-2.0^{\circ} \mathrm{C}\right)$ for the most of the territory. 
Along with this, a very important parameter such as land surface-air temperature $T_{a}$ can also be derived from SEVIRI data. A new method of $T_{a}$ derivation has been developed in (Uspensky et al., 2011). A multiple linear regression model has been constructed that estimates air temperature from satellite-observed LST, solar zenith angle (or related day of the year number), and land elevation. Land surface temperatures estimates from above were used in this scheme to calculate regression coefficients, as well as time-synchronous collocated in-situ measurements from the ground observation network. The development and validation experiments were carried out for the study area for the vegetation seasons of 2006-2009. Data from the above 48 agricultural meteorological stations were used for 8 standard synoptic times a day. All the data were subdivided on separate training and validation data sets. For vegetation season of 2009, an overall bias and standard deviation of calculations are approximately 0 and $1.9-2.1^{\circ} \mathrm{C}$, respectively. The performance of the method is similar to the one presented in (Good, 2009).

\subsection{Remote sensing of snow cover}

Seasonal snow cover is among the most important factors for mid-latitude agriculture. Water accumulated in the snow pack in winter and released through the snowmelt is critical for crop development in early spring. For winter grain crops that are widely grown in Canada, Russia and Ukraine, snow pack presents an insulation material protecting the plants from freezing temperatures. Accurate information on the snow cover extent and variations during the winter season helps to identify areas of potential winterkill and to predict adverse conditions for crops development (e.g. Romanov, 2011).

Although most information on the snow cover distribution and properties for agriculture is traditionally obtained from in-situ observations at ground-based meteorological stations, the use of satellite-based snow products is becoming increasingly popular. First, this section presents a brief overview of current satellite-based snow mapping techniques and of snow products that can be used in agricultural applications. Then, a new technique used in this study and based on synergy of optical and microwave snow cover products available from MODIS and Advanced Microwave Sounding Radiometer (AMSR-E) instruments onboard EOS satellites Terra and Aqua is described.

\subsubsection{Existing snow mapping techniques and products}

To derive information on snow cover from satellite data a number of different techniques, both interactive and automated has been developed and is actively used. The most popular interactive snow product based on visual inspection of satellite optical imagery is Northern Hemipshere snow charts that have been generated by NOAA since 1972. Interactive maps of snow cover are currently produced within a computer-based Interactive Multisensor Snow and Ice Mapping System (IMS) that provides software tools and access to various datasets to facilitate the image analysis and map drawing by human analysts (Helfrich et al, 2007). Daily IMS snow maps are generated at $4 \mathrm{~km}$ resolution and are available from the National Snow and Ice Data Center (NSIDC) at http://nsidc.org/data/g02156.html. Despite some weaknesses associated primarily with subjectivity in the image analysis and interpretation NOAA IMS snow maps present a robust and consistent product. The overall accuracy of daily interactive snow maps is quite high with the yearly mean rate of agreement with surface observations data exceeding 90\% (e.g., Brubaker et al., 2005). Most errors occur 
during fast and large-scale snow advance or retreat or when persistent cloudiness obscures the land surface.

In contrast to interactive techniques the interest to automated algorithms is attracted due to their low exploitation costs and ability to better utilize potentials of satellite data, particularly their high spatial resolution and multi-spectral capability. The two major techniques for mapping and monitoring snow cover from satellites are based, correspondingly on passive observations in the microwave and in the optical (visible to infrared) spectral range.

The advantage of using microwave sensors consists in their ability to "see" through most clouds and to provide information (although quite limited) on snow depth and snow water equivalent (SWE). The primary limitations of microwave measurements are associated with their coarse spatial resolution of $25-50 \mathrm{~km}$, poor sensitivity to shallow and melting snow (Walker and Goodison, 1993) and difficulty to distinguish between snow and frozen rocks and soil (Grody and Basist, 1996). Snow depth and SWE estimates from observations in the microwave are limited only to dry snow packs while corresponding retrieval errors range typically between 50 and $100 \%$ (e.g. Kelly et al., 2003). Global monitoring of snow with microwave sensors data started in 1978 with the launch of Nimbus-7 with Scanning Multichannel Microwave Radiometer (SMMR) onboard and continued with a number of other sensors, including in particular, Special Sensor Microwave Imager (SSM/I) on Defense Meteorological Satellite Program (DMSP) satellites since 1987 (Armstrong and Brodzik 2005) and AMSR-E onboard EOS Aqua satellite since 2002 (Kelly et al, 2003).

As compared to satellite passive microwave measurements, observations in the optical spectral range allow for more accurate mapping of snow cover at higher spatial resolution. The mean accuracy of snow identification in optical bands usually exceeds $90 \%$, but drops to $80-90 \%$ over dense coniferous forests (Simic, et al, 2004, Hall \& Riggs, 2007). Daily global snow cover maps routinely generated with data from MODIS onboard NASA EOS Terra and Aqua satellites at $500 \mathrm{~m}$ spatial resolution (Hall et al, 2002) and from AVHRR onboard NOAA satellites at $4 \mathrm{~km}$ resolution (http://www.star.nesdis.noaa.gov/smcd/emb/snow/HTML/snow.htm). It is important that snow retrievals in the optical spectral bands are possible only under clear sky conditions. Partial improvement in the map area coverage can be achieved with geostationary satellites which provide multiple observations per day and hence increase the chance to see the land surface cloud clear (e.g, De Wildt et al., 2007). With geostationary satellites, however, the map coverage is only regional and is limited to the area within $\sim 65^{\circ} \mathrm{N}$ and $\mathrm{S}$.

Because of physical limitations of both principal snow remote sensing techniques, snow products generated with single sensor data lack either continuity or sufficient accuracy and spatial resolution and thus are hard to use in numerical model applications. In an attempt to improve satellite-based snow cover characterization several techniques have been proposed that combine snow cover observations in the optical and microwave spectral bands (e.g., Romanov et al. (2000), Brodzik et al. (2007), Foster et al. (2011)). The objective of these techniques is to maximize advantages offered by optical and microwave observations, to compensate for their weaknesses and to generate continuous snow maps at the highest possible spatial and temporal resolution. Most often in these algorithms optical snow retrievals are used in clear sky conditions, whereas microwave retrievals complement the optical data when cloudy. 


\subsubsection{Snow cover mapping through synergy of optical and microwave products from EOS satellites}

A new technique used in this study is based on synergy of optical and microwave snow cover products available from MODIS and AMSR-E instruments onboard EOS satellites Terra and Aqua. The objective was to generate an advanced product providing continuous (gap free) characterization of the global snow cover distribution at $5 \mathrm{~km}$ spatial resolution at daily time step.

The algorithm utilizes two NASA daily snow products, MODIS snow cover map on a latitude-longitude grid at $5 \mathrm{~km}$ resolution (labeled by NASA as MOD10C1 and MYD10C1 correspondingly for MODIS Terra and Aqua) and Aqua AMSR-E-based snow water equivalent product AE_DySno. In the developed blending technique we took a cautious approach to the microwave data: microwave retrievals indicating no snow as well as retrievals over mountains were disregarded due to frequent omission of melting snow and shallow snow and frequent overestimates of snow cover in the mountains by microwave algorithms. The remaining microwave retrievals were used to complement snow cover distribution mapped with MODIS data in clear sky conditions. Within this approach some pixels in the daily map may remain undetermined. To eliminate these gaps in the coverage and to achieve continuity in the derived snow cover distribution pixels that remain undetermined in the current day snow map were filled in with the data from the previous day's blended snow map.

All available MODIS and AMSR-E snow products since 2002 have been reprocessed to derive almost 10-years-long time series of daily global snow cover maps. Snow maps in binary format are available at ftp://www.orbit.nesdis.noaa.gov/ pub/ smcd/ emb/ snow/ eos/. An example of a snow cover map generated through synergy of MODIS and AMSR-E data is presented in Fig. 4. To estimate the accuracy of the new snow product we compared it with available surface observations of snow cover. The comparison made for 9 consecutive winter seasons from 2002-2003 to 2010-2011 has shown that the yearly mean agreement of the blended MODIS and AMSR-E snow product to surface observations was $87 \%$. This is only about $3 \%$ less than the accuracy of NOAA interactive snow maps estimated using the same method. The accuracy of the EOS blended product dropped to $80-85 \%$ in the middle of the winter season and increased to close to $100 \%$ in late spring, summer and early fall.

In order to assess consistency of satellite snow retrievals derived from the different satellites, we compared estimates of the derived snow covered area (SCA) from daily snow cover maps of MODIS Terra with ones of MODIS Aqua. The analysis has shown that the SCA derived from MODIS Terra and from MODIS Aqua changes synchronously.

Additionally, we compared dates of snow melt off as determined from satellite data with the dates of snow melt off as determined from the available ground-based observations. The comparison was performed for 48 meteorological stations. The results show that in most cases these dates differ by 1 to 10 days, however in some cases the difference exceeded two weeks (results of 2003 are shown in Fig. 5 as an example). Most probably the primary reason for the difference between satellite and surface estimates of the snow melt-off date consists in the difficulty of detecting shallow wet snow from satellites. However, the observed dates of snow cover decease averaged over the whole area are appeared to be very close to satellite-derived estimates of these dates. 

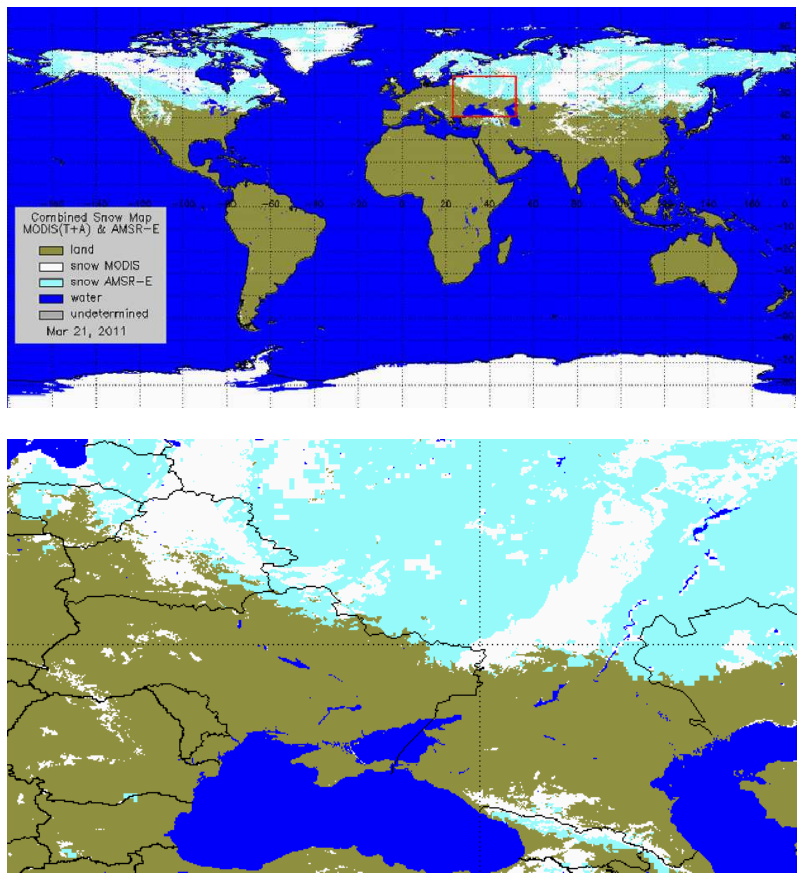

Fig. 4. Example of a blended global daily snow cover map derived from combined data of MODIS and AMSR-E instruments onboard Aqua and Terra satellites (upper) and zoomed in portion of the map covering Eastern Europe. Light blue color and white color represents snow cover identified correspondingly with microwave and optical satellite data (lower).

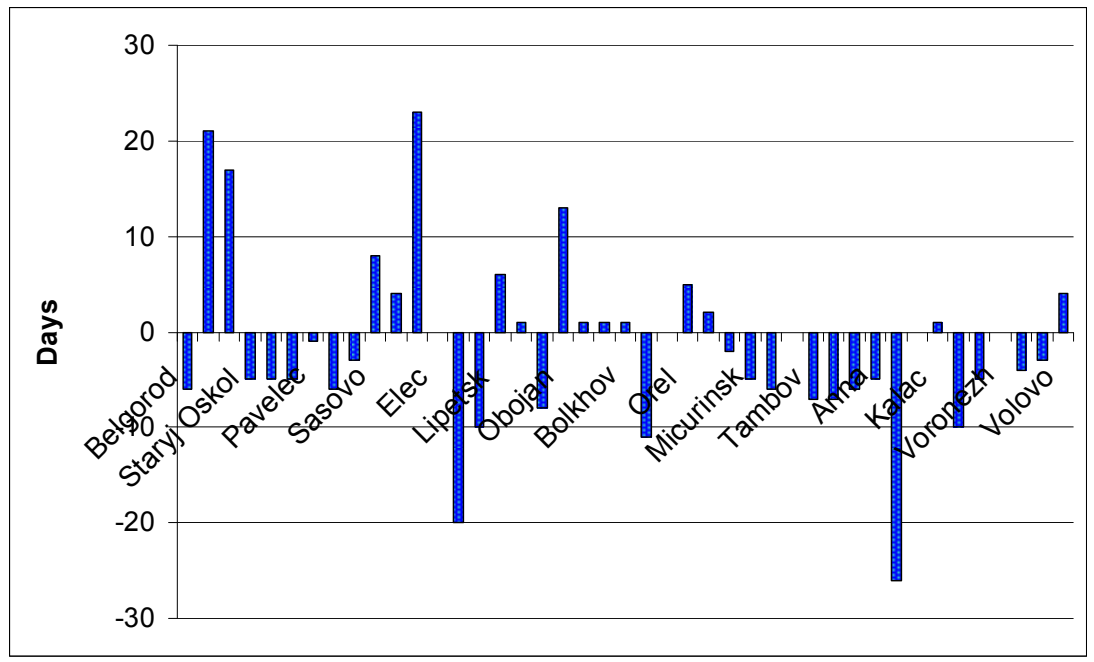

Fig. 5. Difference of snow melt off dates determined from satellite data and from the available ground-based observations 
We consider the blended automated snow products as the most advanced ones providing a reliable and robust characterization of snow cover distribution at the satisfactory accuracy. Potential of using these products in conjunction with land surface model for reproducing snow cover distribution over the agricultural area will be demonstrated in section 5.2.

List of the satellite-derived data, both on land surface characteristics and snow, used in this study is shown in Table 1.

\begin{tabular}{|c|c|c|c|c|c|}
\hline $\begin{array}{l}\text { Land Surface } \\
\text { Characteristic }\end{array}$ & Name of Product & $\begin{array}{l}\text { Sensor/ } \\
\text { Satellite }\end{array}$ & $\begin{array}{l}\text { Latitude- } \\
\text { Longitude } \\
\text { Resolution }\end{array}$ & $\begin{array}{c}\text { Time } \\
\text { Resolution }\end{array}$ & Time Period \\
\hline \multirow{4}{*}{$\begin{array}{l}\text { Land Surface } \\
\text { Temperature }\end{array}$} & NASA_MOD11_B1 & \multirow[b]{2}{*}{$\begin{array}{c}\text { MODIS/ } \\
\text { TERRA\&AQUA }\end{array}$} & $0.05^{\circ} \times 0.05^{\circ}$ & Twice per day & $\begin{array}{c}1 \text { Apr to } 31 \text { Oct } \\
2003-2010\end{array}$ \\
\hline & NASA_MOD11_L2 & & $0.01^{\circ} \times 0.01^{\circ}$ & Twice per day & $\begin{array}{c}1 \text { Mar to } 30 \text { May } \\
2002, \\
1 \text { Mar to } 31 \text { Oct } \\
2003-2010\end{array}$ \\
\hline & \multirow[b]{2}{*}{$\begin{array}{c}\text { Thematic processing } \\
\text { from }\end{array}$} & AVHRR/NOAA & $1^{\prime} \times 1.5^{\prime}$ & Twice per day & $\begin{array}{l}1 \text { Apr to } 31 \text { Oct } \\
1999-2010\end{array}$ \\
\hline & & $\begin{array}{c}\text { SEVIRI/ } \\
\text { METEOSAT-9 }\end{array}$ & $0.06^{\circ} \times 0.06^{\circ}$ & $\begin{array}{c}\text { Every } 15 \mathrm{~min} \\
\text { (at cloud-free } \\
\text { condition) }\end{array}$ & $\begin{array}{l}1 \text { Apr to } 31 \text { Oct } \\
2009-2011\end{array}$ \\
\hline $\begin{array}{l}\text { Land Surface } \\
\text { Albedo }\end{array}$ & NASA_MOD043_C1 & MODIS/TERRA & $0.05^{\circ} \times 0.05^{\circ}$ & $\begin{array}{l}\text { 16-day } \\
\text { product }\end{array}$ & $\begin{array}{c}1 \text { Mar to } 30 \text { May } \\
2003-2010\end{array}$ \\
\hline $\begin{array}{l}\text { Snow Water } \\
\text { Equivalent }\end{array}$ & NASA_AE-DySno & MODIS/AQUA & $0.20^{\circ} \times 0.20^{\circ}$ & Once per day & $\begin{array}{l}20 \text { Jan to } 30 \text { May } \\
2003-2010\end{array}$ \\
\hline $\begin{array}{c}\text { Snow Covered } \\
\text { Area }\end{array}$ & NASA_MOD10_L2 & MODIS/TERRA & $0.01^{\circ} \times 0.01^{\circ}$ & Once per day & $\begin{array}{l}20 \text { Jan to } 30 \text { May } \\
2002-2010\end{array}$ \\
\hline $\begin{array}{l}\text { Vegetation } \\
\text { Cover Fraction }\end{array}$ & $\begin{array}{c}\text { Thematic processing } \\
\text { from }\end{array}$ & AVHRR/NOAA & $1^{\prime} \times 1.5^{\prime}$ & Twice per day & $\begin{array}{l}1 \text { Apr to } 31 \text { Oct } \\
1999-2010\end{array}$ \\
\hline \multirow{2}{*}{$\begin{array}{l}\text { Leaf Area } \\
\text { Index }\end{array}$} & $\begin{array}{c}\text { Thematic processing } \\
\text { from }\end{array}$ & AVHRR/NOAA & $1^{\prime} \times 1.5^{\prime}$ & Twice per day & $\begin{array}{l}1 \text { Apr to } 31 \text { Oct } \\
1999-2010\end{array}$ \\
\hline & NASA_MOD15_A2 & $\begin{array}{c}\text { MODIS/ } \\
\text { TERRA\&AQUA }\end{array}$ & $0.01^{\circ} \times 0.01^{\circ}$ & 8-day product & $\begin{array}{l}1 \text { Apr to } 31 \text { Oct } \\
2003-2010\end{array}$ \\
\hline $\begin{array}{l}\text { Land Cover } \\
\text { Classification }\end{array}$ & Land Cover Type & \multirow{3}{*}{ AVHRR/NOAA } & \multirow{3}{*}{$0.01^{\circ} \times 0.01^{\circ}$} & \multirow{3}{*}{\multicolumn{2}{|c|}{$\begin{array}{c}\text { Static data generated from } \\
\text { AVHRR data }\end{array}$}} \\
\hline $\begin{array}{c}\text { Tree Cover } \\
\text { Fraction }\end{array}$ & Tree Cover Fraction & & & & \\
\hline $\begin{array}{l}\text { Fraction of } \\
\text { Evergreen Tree } \\
\text { Cover }\end{array}$ & $\begin{array}{l}\text { Evergreen Tree } \\
\text { Cover }\end{array}$ & & & & \\
\hline
\end{tabular}

Table 1. Satellite-derived products used in this study 


\section{Remote sensing based land surface model: Structure, calibration and validation by the ground-based data}

The developed comprehensive Remote Sensing Based Land Surface Model (RSBLSM) contains as major components the model of vertical water and heat transfer in the "SoilVegetation-Atmosphere" system (SVAT) for vegetation season as well as the model of vertical water and heat transfer in the "Soil-SNow-Atmosphere" system (SSNAT) for cold season. The first versions of these models were developed in the 1990s (Kuchment et al., 1989; Kuchment \& Startseva, 1991; Kuchment \& Gelfan, 1996). Later, conceptualization of the model was improved through accounting for additional processes (Gelfan et al., 2004; Kuchment et al., 2006), and, importantly, the methods of the model adaption to remote sensing data on land surface were developed (Muzylev et al., 2002; 2005; 2010; Kuchment et al., 2010). Below RSBLSM components used in this paper are described in brief.

\subsection{SVAT component of the RSBLSM system}

The SVAT model is intended for simulating evaporation from bare soil, transpiration by vegetation, vertical latent and sensible heat fluxes, vertically distributed soil water and heat content, soil surface and foliage temperatures, land surface radiation temperature as well as other variables characterized water and heat regimes of soil-vegetation system during a warm season. The model flowchart is shown in Fig. 6.

Land surface is considered as a two-component soil-vegetation system. Water/heat fluxes incoming to and outgoing from bare soil and vegetation cover are accounted for separately. So evapotranspiration $(E v)$ is described as sum of two fluxes: bare soil evaporation $\left(E_{g}\right)$ and transpiration by vegetation $\left(E_{f}\right)$ as

$$
\begin{gathered}
E_{g}=\rho_{a} \cdot\left(r \cdot q^{*}\left(T_{g}\right)-q_{a}\right) / r_{a g} \\
E_{f}=\rho_{a} \cdot\left(q^{*}\left(T_{f}\right)-q_{a}\right) \cdot L A I /\left(r_{a}+r_{s}\right)
\end{gathered}
$$

Sensible heat fluxes from surface of bare soil $H_{g}$ and from vegetation cover $H_{f}$ are calculated as:

$$
\begin{gathered}
H_{g}=\rho_{a} \cdot c_{p} \cdot\left(T_{g}-T\right) / r_{a g}, \\
H_{f}=\rho_{a} \cdot c_{p} \cdot\left(T_{f}-T\right) / r_{a}
\end{gathered}
$$

where $T_{g}$ and $T_{f}$ are the soil surface and the foliage temperatures, respectively, $T$ and $q_{a}$ are the air temperature and specific air humidity at $2 \mathrm{~m}$ height, respectively; $q^{*}\left(T_{g}\right)$ and $q^{*}\left(T_{f}\right)$ are the specific air saturation humidity at the temperatures $T_{g}$ and $T_{f}$, correspondingly, $r$ is the relative air humidity near the soil surface, $r_{a g}$ and $r_{a}$ are the aerodynamic resistance between soil surfaces and foliage and between foliage and atmosphere, respectively,

$$
r_{a g}=\left(C_{g} \cdot U\right)^{-1}
$$




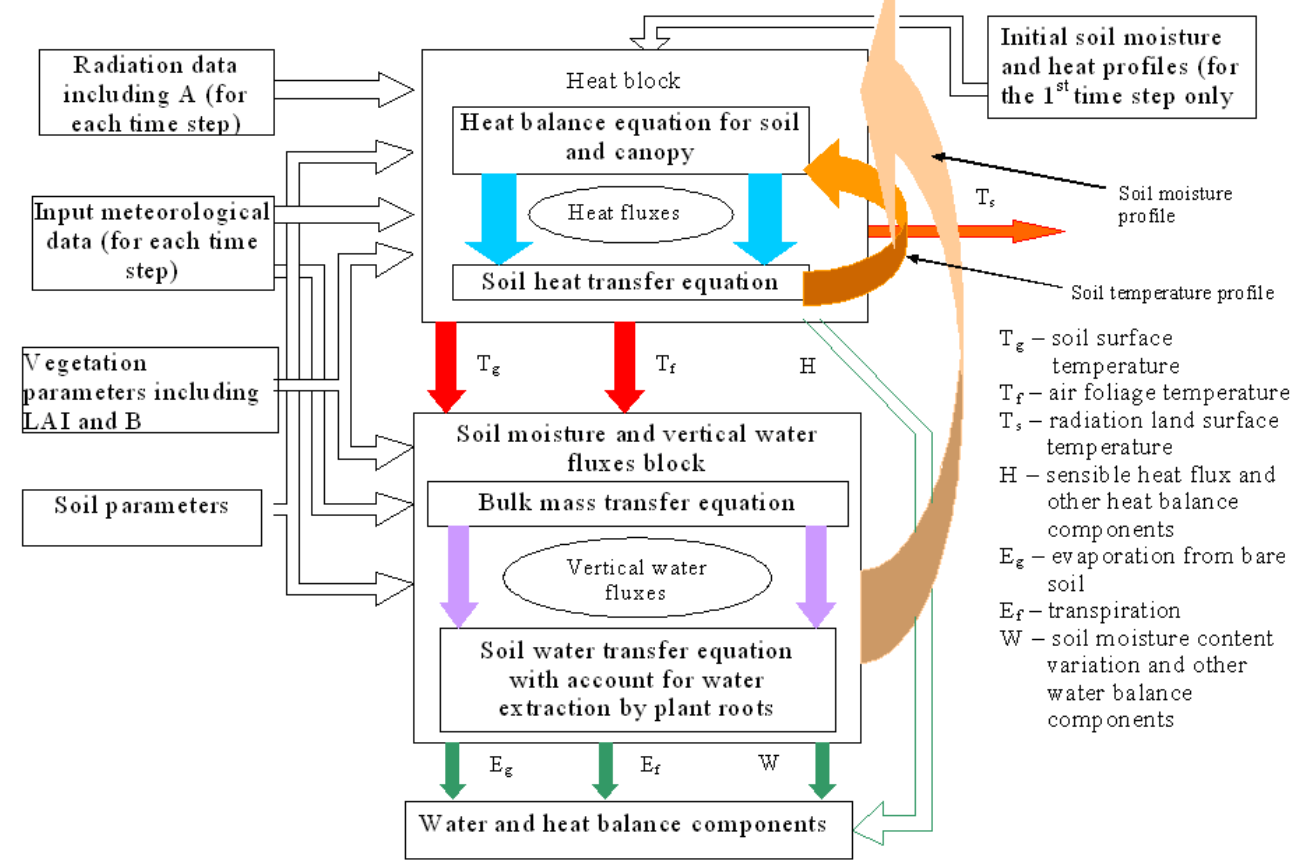

Fig. 6. The SVAT model flowchart

$$
r_{a}=\left(C_{e} \cdot U\right)^{-1},
$$

where $C_{e}$ and $C_{g}$ are the vapour transfer coefficients at the canopy level and at the ground one, respectively, depending on the surface roughness; $U$ is the wind velocity at $10 \mathrm{~m}$ height, $r_{s}$ is the stomatal resistance calculated by formula

$$
r_{s}=r_{0} \frac{\psi\left(\theta_{w p}\right)-\varsigma \psi_{f}}{\psi\left(\theta_{w p}\right)-\psi_{f}}
$$

$r_{0}$ is the minimum stomatal resistance, $\psi\left(\theta_{w p}\right)$ is the soil matrix potential corresponding to wilting point $\theta_{w p}, \varsigma$ is the coefficient, LAI is the leaf area index, $\rho_{a}$ is the air density, $c_{p}$ is the specific heat at constant pressure.

The relative air humidity $r$ near the soil surface in (1a) is defined by formula

$$
r=\exp \frac{M g \psi(\theta)}{R\left(T_{g}+273\right)}
$$

where $\theta$ is the volumetric soil moisture content, $\psi(\theta)$ is the soil matrix potential, $M$ is the molecular mass of water, $g$ is the acceleration of gravity, $R$ is the universal gas constant.

To describe water transfer in the soil, the equation of soil moisture diffusion is applied taking into consideration water extraction by plant roots 


$$
\frac{\partial \theta}{\partial t}=\frac{\partial}{\partial z}\left[D(\theta) \frac{\partial \theta}{\partial z}-K(\theta)\right]-R(\theta, z)
$$

where $K(\theta)$ is the hydraulic conductivity of soil, $D=K(\partial \psi / \partial \theta)$ is the soil moisture diffusion coefficient, $R(\theta, z)$ is the intensity of water extraction by plant roots

$$
R(\theta, z)=-K(\theta) \cdot\left[\psi_{r}-\psi(\theta)\right] \cdot b_{r} \cdot \rho_{r}(z)
$$

$\psi_{r}$ and $\rho_{r}(z)$ are the rootage water potential and the density, respectively, $b_{r}$ is the coefficient.

The soil matrix potential $\psi(\theta)$ and the soil hydraulic conductivity $K(\theta)$ can be assigned using different parametrizations. We compared some of them (Brooks \& Corey, 1964; Clapp \& Hornberger, 1978; van Genuhten, 1980) and found that they give similar simulation results. Hereafter, van Genuhten's formulas are used:

$$
\begin{gathered}
\psi(\theta)=-\frac{\left(S^{-1 / m}-1\right)^{1 / n}}{\alpha} \\
K=K_{0} S^{0.5}\left[1-\left(1-S^{1 / m}\right)^{m}\right]^{2}
\end{gathered}
$$

where $S=\left(\theta-\theta_{r}\right)\left(\theta_{s}-\theta_{r}\right)^{-1}$ is the relative saturation; $\theta_{s}$ and $\theta_{r}$ are the residual and the saturated water contents respectively; $K_{0}$ is the saturated hydraulic conductivity; $\alpha>0$ is the parameter, which is related to the inverse of the air entry pressure; $m=1-n^{-1}, n>1$ is the parameter, which is a measure of the pore-size distribution.

The foliage water potential $\psi_{f}$ is assumed to be expressed in terms of $\psi_{r}$ using the relationship

$$
\psi_{f}=\psi_{r}-r_{r} \rho_{w} \int_{0}^{Z_{\max }} R(\theta, z) d z
$$

where $r_{r}$ is the rootage resistance, $Z_{\max }$ is the maximum length of roots, and $\rho_{w}$ is the water density.

Heat transfer within a soil layer is described by

$$
C_{e f f}(\theta) \frac{\partial T}{\partial t}=\frac{\partial}{\partial z}\left(\lambda(\theta) \frac{\partial T}{\partial z}\right)
$$

where $C_{\text {eff }}(\theta)$ and $\lambda(\theta)$ are the effective soil heat capacity and the soil heat conductivity.

The soil surface temperature $T_{g}$ is calculated from Eq. (12). The foliage temperature $T_{f}$ is obtained from the heat balance equation for the vegetation cover neglecting its heat content. Both $T_{g}$ and $T_{f}$ are used for assessing latent and sensible heat fluxes from bare soil and vegetation surfaces (Eqs. (1a) - (2b)).

The land surface radiation temperature $T_{s}$ is calculated from the long-wave radiation balance equation 


$$
\sigma \cdot T_{s}^{4}=R_{a}-R_{l f}-R_{\mathrm{lg}}
$$

where $R_{a}$ is the atmosphere counterradiation, $R_{l f}$ and $R_{\mathrm{lg}}$ are long-wave components of radiation balance for vegetation and bare soil, respectively, calculated as functions of the measured meteorological variables, $\sigma$ is the Stefan-Boltzmann constant.

The input variables of the SVAT model are incoming radiation, air temperature, humidity and pressure, cloudiness, precipitation, wind speed assigned from the standard meteorological observations. Initial conditions for Eqs. (7) and (12), namely soil moisture and temperature profiles at the beginning of the vegetation season, are calculated by Eqs. (25), (26) (see the following section) through spin-up simulations of soil moisture and heat regimes during a winter previous to vegetation season.

Eqs. (7), (12) are numerically integrated by an implicit, four-point finite difference scheme with the time and spatial steps of 3 hours and $10 \mathrm{~cm}$, respectively.

Spatial heterogeneity of land surface characteristics is taking into account in the model by the mosaic approach, i.e. by selection of plots on the studied territory with different soils, land-use and vegetation types which correspond to specific parameter values. Soils are characterized by bulk density, maximum hygroscopicity, porosity, field capacity, and saturated hydraulic conductivity. The heterogeneity of vegetation is represented by the minimum stomatal resistance, the leaf area index LAI, vegetation cover fraction $B$, and the aerodynamic resistance $r_{a}$.

The principal model parameters have been adjusted by calibration against groundmeasured soil water content $W$, evapotranspiration $E v$, vertical soil moisture profiles, and soil surface temperature. Also, the values of several parameters have been retrieved from the specific measurements at agricultural meteorological stations, some of them have been estimated using satellite data, and the values of certain parameters have been derived from literature sources. The spatial distributions of the most meteorological parameter values (being input model variables) have been built using interpolation procedures. The water and heat balance components for the entire considered territory have been calculated as weight-averages accounting for size of the area occupied by specific soil and vegetation.

In developing version of the model designed for utilizing satellite estimates of the land surface characteristics (built in a quasi-regular grid nodes) the uniform grid with $3 \times 3$ AVHRR/NOAA pixel cells $\left(\sim 7 \times 5 \mathrm{~km}^{2}\right)$ has been superimposed on the entire investigated territory divided into plots with different soils and vegetation. Grid size for other sensors was assigned as close to one of AVHRR/NOAA. (Note, that pixel size for the IR channels of the AVHRR radiometer is $1^{\prime}$ in latitude and 1.5' in longitude, for similar MODIS channels resolution is equal to 1 and $4.8 \mathrm{~km}$, and for the same channels of SEVIRI it is $0.05^{\circ}$ in latitude and $0.06^{\circ}$ in longitude). For nodes of the grids there have been built AVHRR-derived estimates of $T_{a}, T_{s g}, T_{\text {s.eff }}, N D V I, E, B$, and $L A I$, MODIS-derived estimates of $T_{l s}, E$, $N D V I, B$ and $L A I$, and SEVIRI-derived estimates of $T_{l s}$. Maps of some AVHRR-derived land surface characteristics for part of the study area are shown in Fig. 7. There have been also defined model parameters and input variables as well as there have been calculated the values of $E v, W$ and other water and heat balance components together with $T_{f}, T_{g}$ and $T_{s}$. 


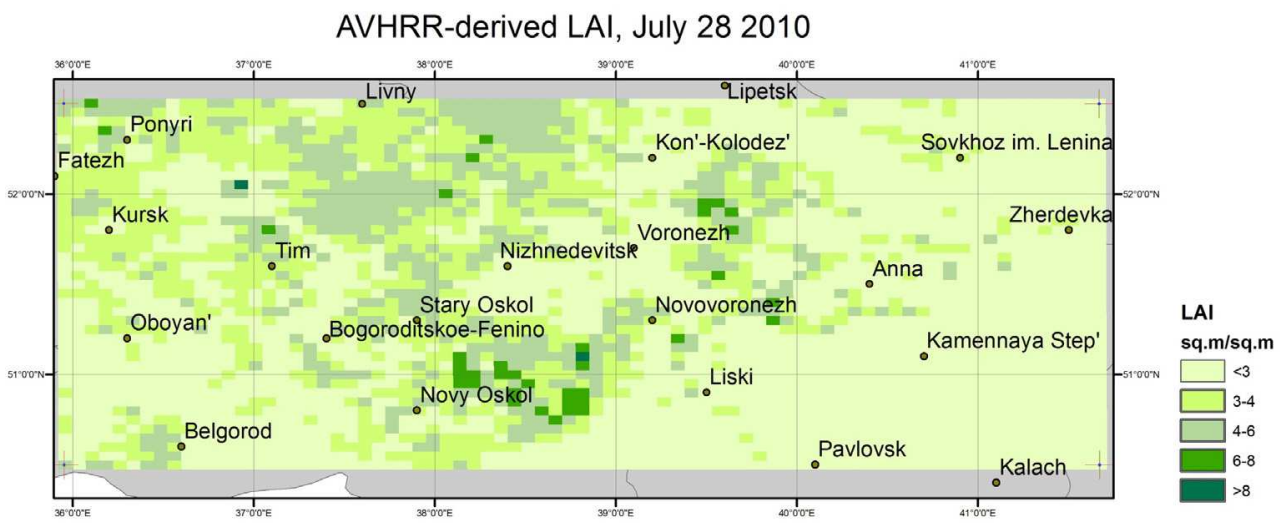

Vegetation Cover Fraction (VCF), July 282010

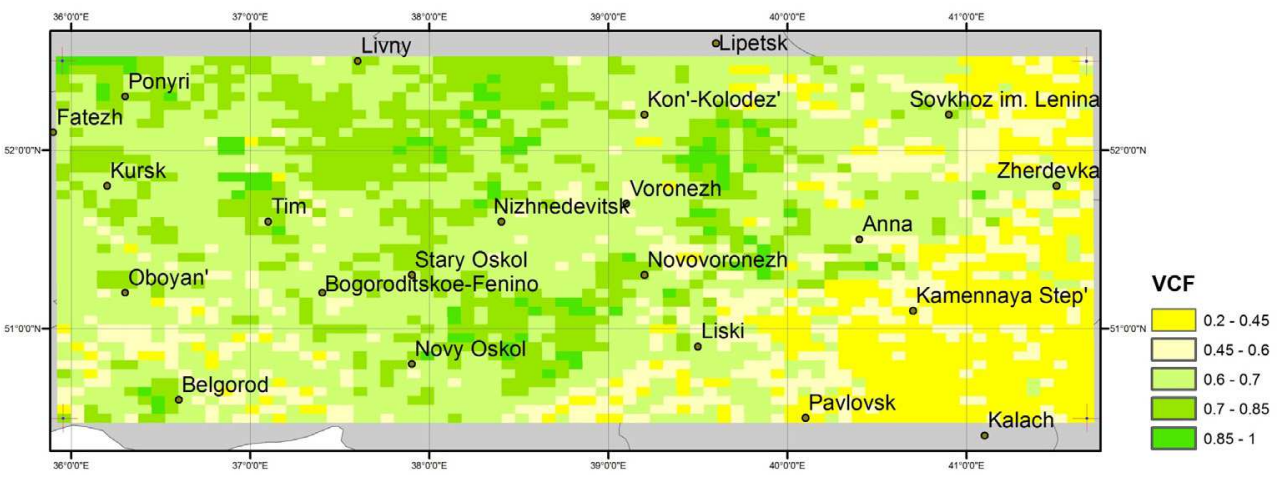

Land Surface Temperature (LST), July 282010

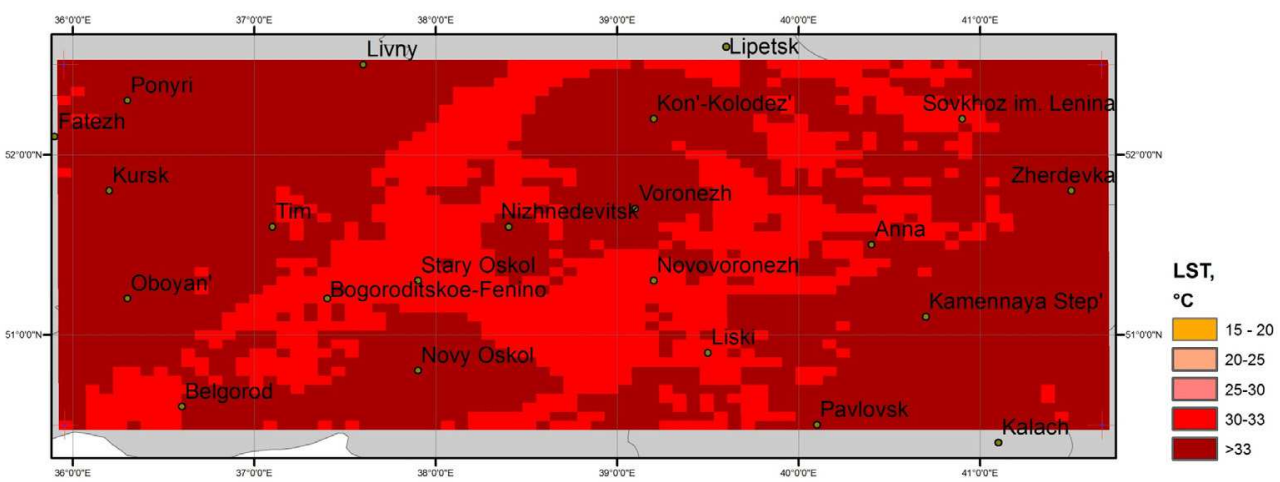

Fig. 7. Maps of some AVHRR-derived land surface characteristics 


\subsection{SSNAT component of the RSBLSM system}

SSNAT model describes hydrothermal processes in soil and snow cover during a cold season, including processes of snow accumulation and melt, changes of soil moisture and temperature during soil freezing and thawing, as well as snowmelt water infiltration.

To simulate temporal changes of the snow depth and density, heat content of snow, water phase transformation and other processes within a snowpack during snow accumulation and melt, one-layer snow model proposed in (Kuchment, Gelfan, 1996) has been applied. The main equations of the model are written as:

$$
\begin{gathered}
\frac{d H}{d t}=\rho_{w}\left[X_{s} \rho_{0}^{-1}-\left(S+E_{s}\right)\left(\rho_{i} i\right)^{-1}\right]-V \\
\frac{d}{d t}(i H)=\frac{\rho_{w}}{\rho_{i}}\left(X_{s}-S-E_{s}\right)+S_{i} \\
\frac{d}{d t}(w H)=X_{l}+S-E_{l}-R-\frac{\rho_{i}}{\rho_{w}} S_{i} \\
c_{s} \frac{d}{d t}\left(T_{s} H\right)=Q_{a}-Q_{g}-\rho_{w} L S+\rho_{i} L S_{i}
\end{gathered}
$$

where $H$ is the snow depth; $i$ and $w$ are the vertically averaged volumetric contents of ice and liquid water, respectively; $T_{s}$ is the vertically averaged temperature of snowpack; $S$ is the melt rate; $S_{i}$ is the rate of freezing of liquid water in snow, $E_{l}$ is the rate of liquid water evaporation from snow; $E_{s}$ is the rate of snow sublimation, $Q_{a}$ is the net heat flux at the snow surface; $Q_{g}$ is the ground heat flux; $X_{s}$ and $X_{l}$ are the snowfall and rainfall rates, respectively (partitioning of the total precipitation, $X$, into solid and liquid phase is a function of the air temperature); $V$ is the snowpack compression rate; $R$ is the snowmelt outflow from snowpack; $c_{S}$ is the specific heat capacity of snow; $\rho_{w}, \rho_{i}$, and $\rho_{0}$ are the densities of water, ice, and fresh-fallen snow, respectively; $L$ is the latent heat of ice fusion.

The melt rate $S$ is found from the energy balance of the snowpack at zero snow temperature as:

$$
S=\left\{\begin{array}{l}
\left(Q_{a}-Q_{g}\right)\left(\rho_{w} L\right)^{-1}=\left(Q_{s w}+Q_{l w}-Q_{l s}+Q_{T}+Q_{E}+Q_{P}-Q_{g}\right)\left(\rho_{w} L\right)^{-1}, Q_{a}-Q_{g}>0 \\
0, Q_{a}-Q_{g}<0
\end{array}\right.
$$

where $Q_{s w}$ is the net short wave radiation; $Q_{l w}$ is the downward long wave radiation; $Q_{l s}$ is the upward long wave radiation from snow; $Q_{T}$ is the sensible heat exchange; $Q_{E}$ is the latent heat exchange; $Q_{P}$ is the heat content of liquid precipitation.

The heat flux components of $Q_{a}$ for an open agricultural site are calculated by the empirical relationships using the observed meteorological variables (air temperature, air humidity, wind speed, precipitation, and cloudiness) as the inputs.

The rate $S_{i}$ of freezing of liquid water in snowpack is calculated as: 


$$
S_{i}=\left\{\begin{array}{l}
H \frac{d w}{d t}, T_{s}=0^{\circ} \mathrm{C} \wedge Q_{a}-Q_{g}<0 \wedge \frac{\left|Q_{a}-Q_{g}\right|}{\rho_{i} L} \geq H \frac{d w}{d t} \\
\frac{\left|Q_{a}-Q_{g}\right|}{\rho_{i} L}, T_{s}=0^{\circ} \mathrm{C} \wedge Q_{a}-Q_{g}<0 \wedge \frac{\left|Q_{a}-Q_{g}\right|}{\rho_{i} L}<H \frac{d w}{d t} \\
0, T_{s}=0^{\circ} \mathrm{C} \wedge Q_{a}-Q_{g} \geq 0 \\
X_{l}, T_{s}<0^{\circ} \mathrm{C}
\end{array}\right.
$$

The snowpack compression rate $V\left(\right.$ in $\left.\mathrm{cm} \mathrm{s}^{-1}\right)$ is found from:

$$
V=\frac{v_{1} \rho_{s}}{\exp \left(v_{2} T_{s}+v_{3} \rho_{s}\right)} \frac{H^{2}}{2}
$$

where $\rho_{s}$ is the density of snowpack (in $\mathrm{g} \mathrm{cm}^{-3}$ ) equal to $\rho_{s}=\rho_{i} i+\rho_{w} w ; v_{1}, v_{2}$, and $v_{3}$ are the coefficients equal to $2.8 \times 10^{-6} \mathrm{~cm}^{2} \mathrm{~s}^{-1} \mathrm{~g}^{-1} ;-0.08 \mathrm{OC}^{-1} ; 21 \mathrm{~cm}^{3} \mathrm{~g}^{-1}$, respectively.

The outflow of liquid water from snow is calculated as:

$$
R=\left\{\begin{array}{l}
X_{l}+S-E_{l}-w_{\max } \frac{d H}{d t}, w=w_{\max } \\
0, w<w_{\max }
\end{array}\right.
$$

where $w_{\max }$ is the holding capacity of snowpack related to its density $\rho_{s}$ as

$$
w_{\max }=0.11-0.11 \frac{\rho_{s}}{\rho_{w}}
$$

Numerical integration of the Eqs. (14) - (17) is carried out by an explicit finite-difference scheme with the time-step of 3 hours.

To calibrate the snow pack model for the study area, the meteorological data from 48 stations for the period from 1 November 2001 to 31 May 2002 were used. Then the model was validated against snow depth observations during the winter-spring seasons of 20022003 and 2003-2004. The comparison of snow modeling results with the observed snow depth at the ground-based stations has demonstrated a good correspondence between the two datasets. The standard error of the simulated snow depth was $5.8 \mathrm{~cm}$ during the calibration stage and $7.7 \mathrm{~cm}$ at the validation stage.

Water and heat transfer in a soil during the processes of soil freezing, thawing and infiltration of water are described by the following equations (Gelfan, 2006):

$$
\begin{gathered}
\frac{\partial W}{\partial t}=\frac{\partial}{\partial z}\left(D_{\theta} \frac{\partial \theta}{\partial z}+D_{I} \frac{\partial I}{\partial z}-K\right) \\
c_{T} \frac{\partial T}{\partial t}-\rho_{w} L \frac{\partial W}{\partial t}=\frac{\partial}{\partial z}\left(\lambda \frac{\partial T}{\partial z}\right)+\rho_{w} c_{w}\left(D_{\theta} \frac{\partial \theta}{\partial z}+D_{I} \frac{\partial I}{\partial z}-K\right) \frac{\partial T}{\partial z}
\end{gathered}
$$


where $W$ and $I$ are the total water content and ice content of soil, respectively $\left(W=\theta+\rho_{i} I / \rho_{w}\right) ; c_{T}=c_{e f f}+\rho_{w} L(\partial \theta / \partial T) ; c_{e f f}$ is the effective heat capacity of soil equals $c_{\text {eff }}=\rho_{g} c_{g}(1-P)+\rho_{w} c_{w} \theta+\rho_{i} c_{i} I ; \rho$ and $c$ are the soil density and the specific heat capacity, respectively (indexes $w, i$ and $g$ refer to water, ice and soil matrix, respectively); $P$ is the soil porosity; $D_{\theta}=K(\partial \psi / \partial \theta)_{I} ; D_{I}=K(\partial \psi / \partial I)_{\theta} ; \psi=\psi(\theta, I)$ is the matrix potential of soil.

If soil is frozen $(I(z, t) \neq 0)$, than hydraulic and thermal characteristics of soil are functions of ice content, i.e. $K=K(\theta, I), \lambda=\lambda(\theta, I)$. One can see that for an unfrozen condition $(I(z, t)=0)$, Eq. (23) reduces to Eq. (7) (neglecting water extraction by plant roots) and Eq. (24) reduces to Eq. (12).

The matrix potential, $\psi=\psi(\theta, I)$, and the hydraulic conductivity, $K=K(\theta, I)$ are determined from (Gelfan, 2006):

$$
\begin{gathered}
\psi(\theta, I)=-\frac{\left(S_{f}^{-1 / m}-1\right)^{1 / n}}{\alpha} \times\left[\frac{\theta_{0}-\theta_{r}}{\theta_{0}-I-\theta_{r}}+\frac{\theta_{r}}{\theta}\left(1-\frac{\theta_{0}-\theta_{r}}{\theta_{0}-I-\theta_{r}}\right)\right](1+8 I)^{2} \\
K(\theta, I)=K_{0} S_{f}^{0.5}\left[\frac{1-\left(1-S_{f}^{1 / m}\right)^{m}}{(1+8 I)}\right]^{2}
\end{gathered}
$$

where $S_{f}=\left(\theta-\theta_{r}\right)\left(\theta_{0}-I-\theta_{r}\right)^{-1}$ is the relative saturation of frozen soil.

Note, that under $I(z, t)=0$ formulas (25), (26) reduce to the van Genuchten's formulas (9), (10) for an unfrozen condition.

The values of $\theta_{0}$ and $\theta_{r}$ are assumed to be equal to the measured soil porosity and maximum hydroscopicity, respectively. The values of $a, n, c_{T}$, and $\lambda$ are calculated from the measured soil characteristics, such as bulk density, field capacity, and wilting point by the formulas presented in Gelfan (2006).

Equations (23) and (24) are numerically integrated by an implicit, four-point finite difference scheme with the time and spatial steps of the finite difference scheme of 1 hour and $10 \mathrm{~cm}$, respectively.

\section{Results}

\subsection{Satellite based modeling water and heat regimes of the study region during a vegetation season}

The model has been verified by comparing the calculated and measured vertical soil moisture and temperature profiles, values of land surface temperature, radiation balance, soil water content of one-meter soil layer, and evapotranspiration. Results of such a collation for several characteristics above are shown in the Figs. 8-10 by the example of some meteorological stations located in the study area.

Moreover, there has been executed comparison of modeled values of $T_{f}, T_{g}$ and $T_{s}$ with their satellite-derived analogues $T_{a}, T_{s g}$ and $T_{\text {s.eff }}$ for AVHRR and $T_{l s}$ for MODIS and 

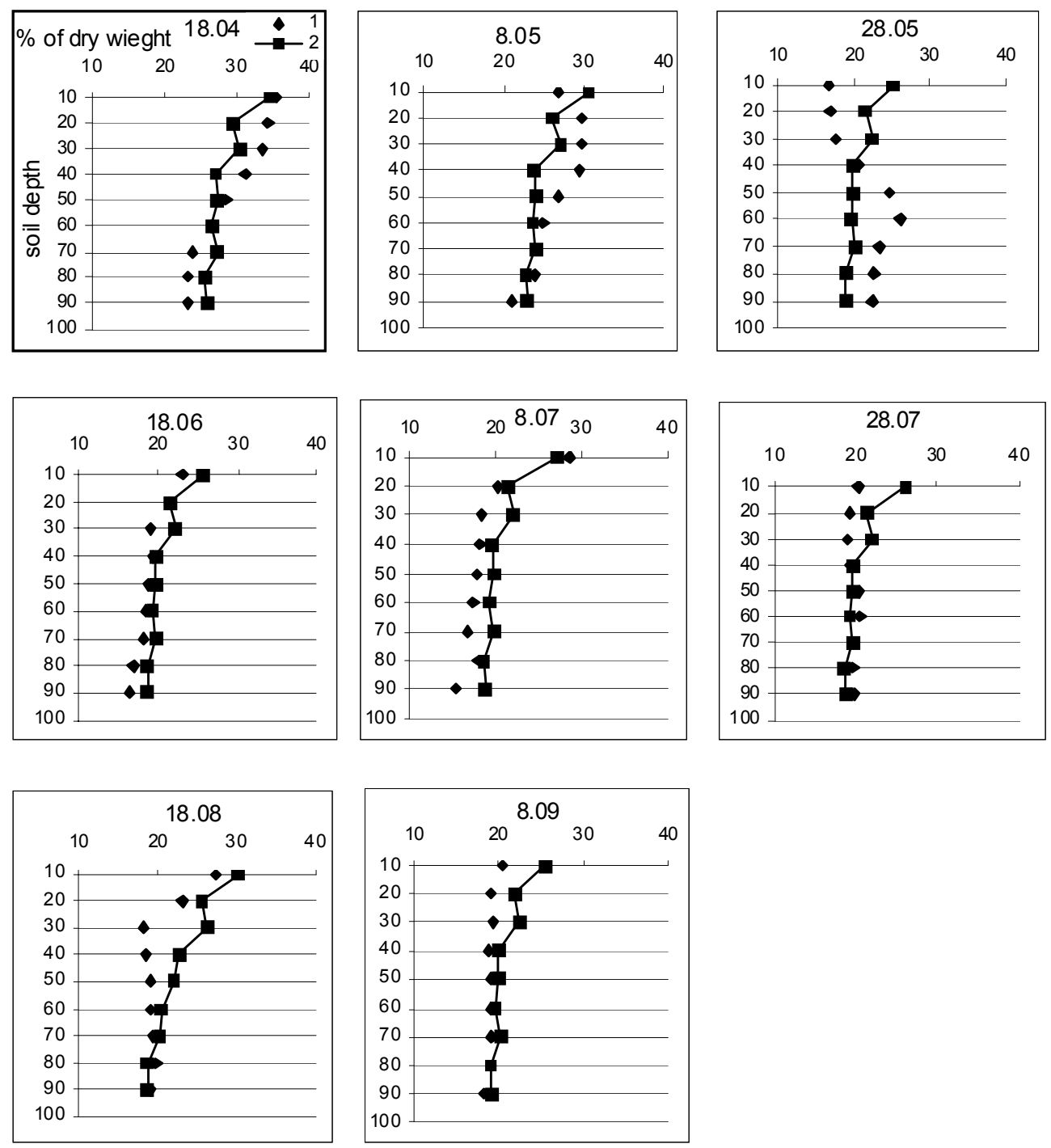

Fig. 8. Modeled (1) and measured (2) vertical soil moisture profiles for perennial grasses at water balance station Nizhnedevitsk for 2003 vegetation season 

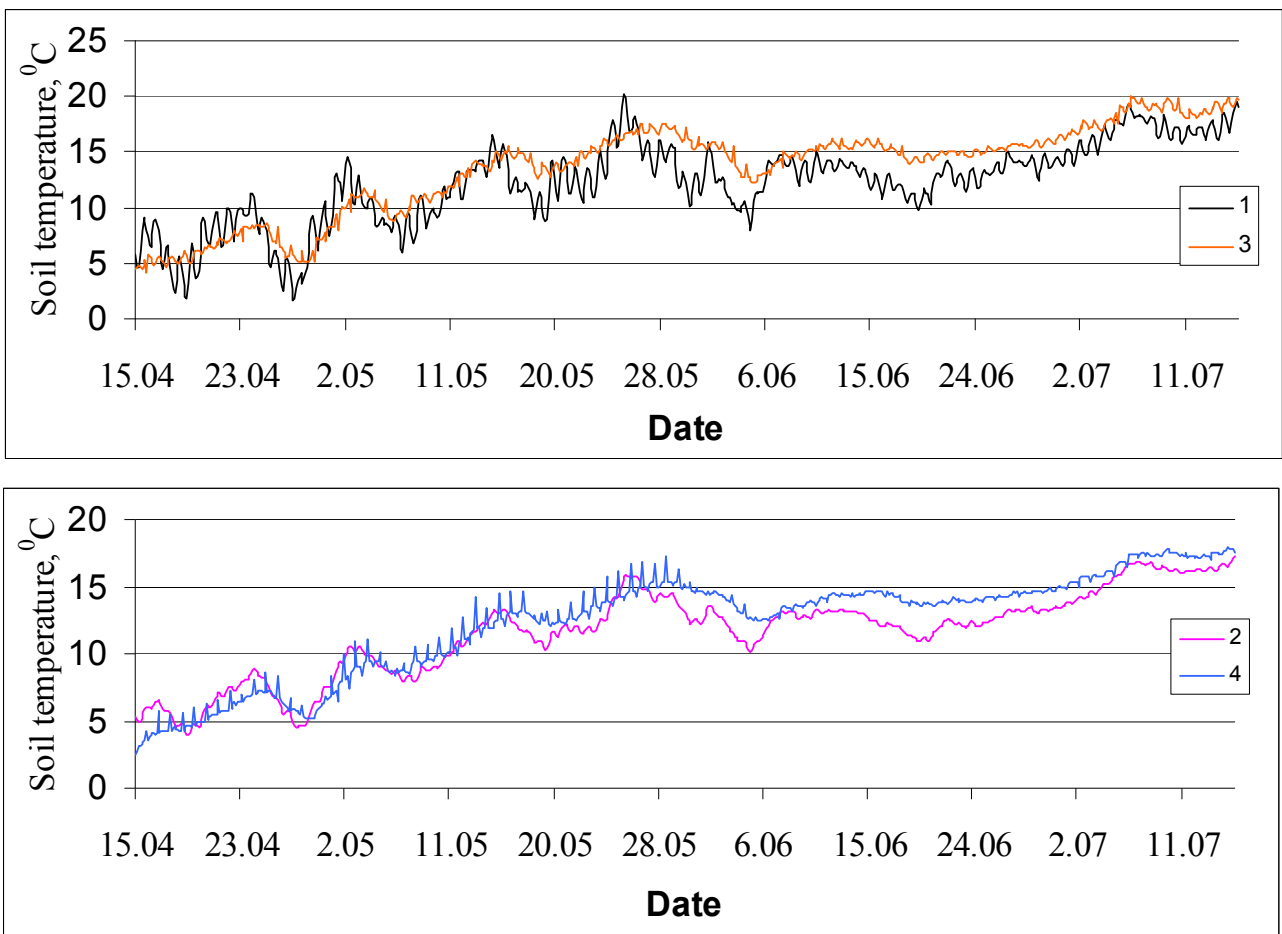

Fig. 9. Soil temperature under vegetation cover modeled for the depth 20 (1) and 40 (2) cm and measured at the same depths for perennial grasses at Nizhnedevitsk water balance station in 2003

SEVIRI. For most terms of each considered vegetation season the differences $T_{\text {s.eff }}-T_{s}$, $T_{a}-T_{f}$, and $T_{s g}-T_{g}$ have not exceed the standard errors of AVHRR-derived estimates of $T_{\text {s.eff }}, T_{a}$ and $T_{s g}$ as one can see from Fig. 11 illustrating this result for the part of the study area. Separate local spots with a difference of $20^{\circ} \mathrm{C}$ on these figures correspond to the clouds above given plots. 

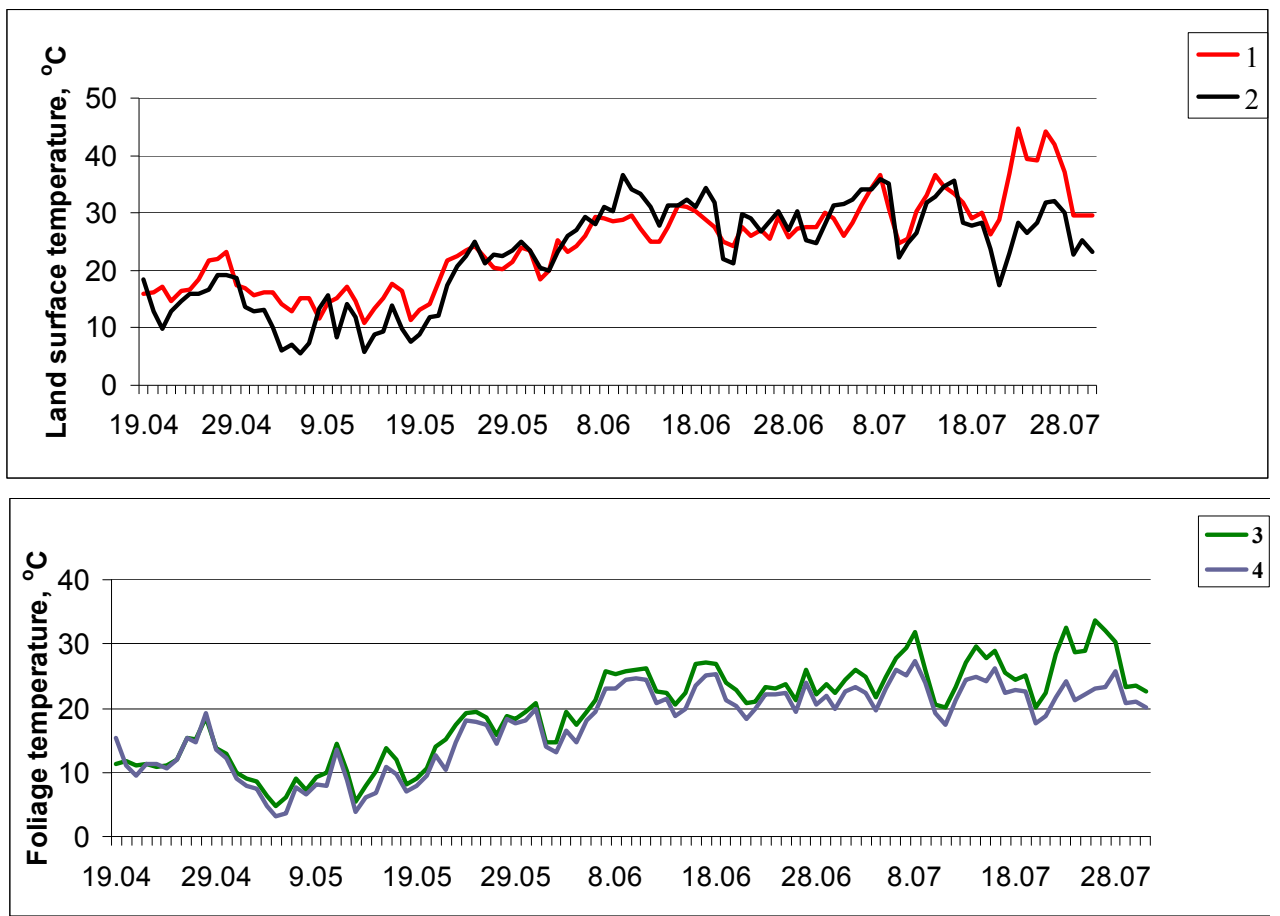

Fig. 10. Modeled (1) and measured (2) soil surface temperatures, modeled foliage temperature (3) and measured air temperature (4) for winter wheat at agricultural meteorological station Petrinka for vegetation season 1999
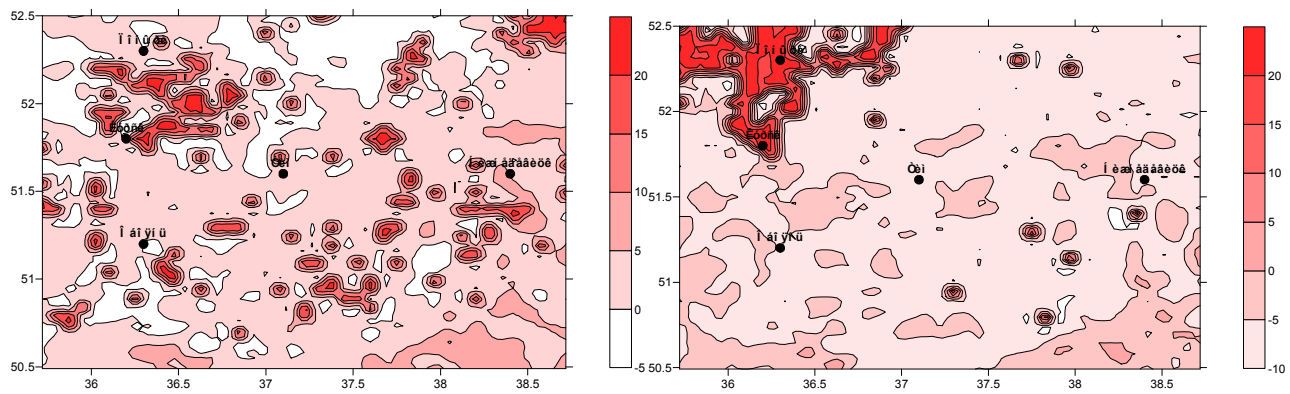

Fig. 11. LST difference map $\left(\Delta \mathrm{T}=\mathrm{T}_{\text {s.eff }}(\mathrm{AVHRR})-\mathrm{T}_{\mathrm{s}}(\mathrm{MODEL})\right)$ for part of the study region of 23,500 km² with spacing of $\sim 5 \mathrm{~km}, 11.00$ GMT 27 May (left) and 12 August (right) 2009

Similar distributions have been also built for the difference of $T_{l s}(M O D I S)-T_{s}(M O D E L)$. Results of comparing SEVIRI-derived temperature $T_{l s}$ defined by continuous measurements during 6-day interval of the vegetation season 2009 with three-hour ground-based observation data on air temperature $T$ at agricultural meteorological station Livny and with modeled temperature $T_{f}$ calculated using the same ground-based data are shown in Fig. 12. As seen from this figure, the temporal behavior of these variables is quite close. 
To discover relevance of the model parameters (stomatal resistance $r_{0}$, leaf area index $L A I$, soil and vegetation albedos $\left(A_{g}, A_{f}\right)$ and emissivities $\left(E_{s}, E_{p}\right)$ for describing the water and heat exchange processes, sensitivity of the model (in particular, of the quantities $E v$ and $T_{s}$ ) to these parameter variations has been investigated. In (Kuchment \& Startseva, 1991) it has been shown that Ev is strongly influenced by $r_{0}$. The present study has confirmed this effect. Particularly, changing the values of $r_{0}$ for winter wheat and perennial grasses by 20 and $60 \%$ results in changing the values of $E v$ by $4-5$ and $8-10 \mathrm{~mm}$ per decade, correspondingly. Strong sensitivity of quantities $E v$ and $T_{s}$ to variations of LAI was also found. It was particularly notable in periods of rapid plant growth, their yellowing, mowing, as well as in the beginning of vegetation season.

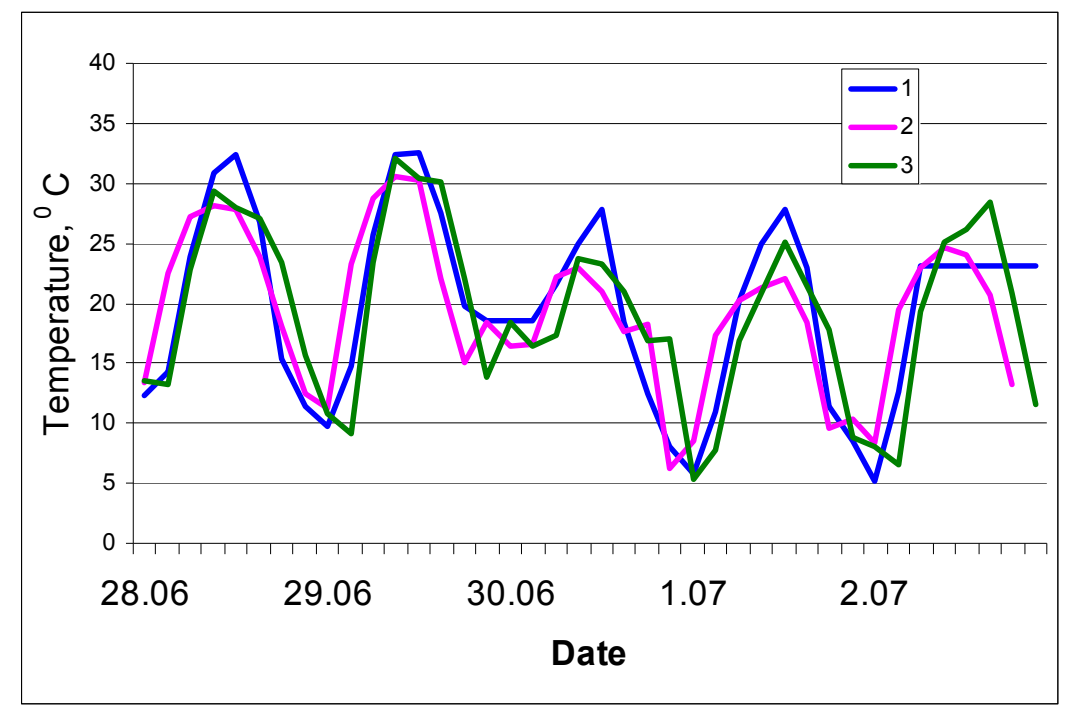

Fig. 12. SEVIRI-derived LST (1), air temperature (2), and air vegetation temperature modeled using three-hour ground observation data (3) on 28.06.-03.07.2009 at agricultural meteorological station Livny

Changing the relative values of $L A I$ by 0.1 and 0.2 resulted in changing the values of $E v$ by 2-2.5 and 3-3.5 mm per decade and $T_{s}$ by 1.0-1.2 and 1.4-1.6 ${ }^{\circ} \mathrm{C}$, respectively, and changing the maximum values of $L A I$ from 3 to 5 leads to increase of $E v \quad 7-8 \mathrm{~mm}$ per decade and decrease of $T_{s} \sim 2^{\circ} \mathrm{C}$. Numerical experiments with a shift of time mowing led to changing values of $E v$ for perennial grasses to $15-17 \mathrm{~mm}$ per decade and values of $T_{s}$ to more than $3^{\circ} \mathrm{C}$ (fig. 13).

Such sensitivity makes it possible to select appropriately the values of $L A I$ at the specific site, that, in turn, leads to close to actual assessment of vegetation cover fraction $B$ that is shown below. The influence of the integral soil and vegetation albedos $A_{g}$ and $A_{f}$ on the values of $E v$ and $T_{s}$ was different. Evapotranspiration was varied more when changing $A_{f}$ whereas temperature $T_{s}$ was changed significantly by variation of $A_{g}$. Particularly, change of $A_{g}$ by 0.2 led to changes of $E v$ for several crops by $1.5-2.5 \mathrm{~mm}$ per decade and corresponding 

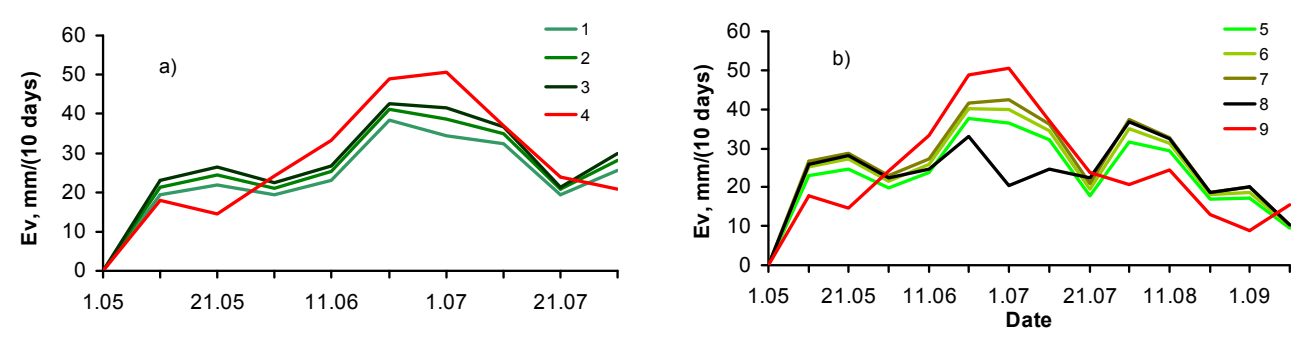

Fig. 13. Modeled values of evapotranspiration Ev for 1997 vegetation season at agricultural meteorological station Petrinka for winter wheat (a); perennial grasses (b) and different values of $\mathrm{LAI}_{\max }: 2.5$ (1); 3.5 (2); 4.5 (3); 3.0 (5); 4.0 (6); 5.0 (7); (8) 4.5 with shift of mowing day for 3 weeks. (4) and (9) corresponds to measured values of Ev for perennial grasses.

variations of $T_{s}$ reached $3^{\circ} \mathrm{C}$ and more. Similar variations of $A_{f}$ led to changes of $E v$ by $4-5$ $\mathrm{mm}$ and more per decade and also of $T_{s}$ by $1.5-2^{\circ} \mathrm{C}$. Direct effect of soil and vegetation emissivities $E_{s}$ and $E_{p}$ on $E v$ and $T_{s}$ was negligible.

The main conclusion from all experiments described above is that the key parameters affecting evapotranspiration and soil water content under wet soil conditions are $r_{0}$ and shading parameters $L A I$ and $B$. At the same time the influence of the latter two is often more substantial than of the first one. Under dry soil conditions (usually occurring when increasing land surface temperature), this effect becomes less noticeable and the value of evapotranspiration is mainly determined by soil water content of the upper one meter soil layer.

High sensitivity of $E v$ and $T_{s}$ to $L A I$ variations as well as possibility to control current values of $L A I$ by comparing modeled $T_{f}, T_{g}$ and $T_{s}$ with satellite-derived $T_{a}, T_{s g}$ and $T_{\text {s.eff }}$ allowed specifying time behavior of $L A I$ for several crops in the absence of phytometry data. Satellite-based values of $L A I$ were estimated using empirical relationships between LAI and NDVI for grasslands (Biospheric Aspects, 1993) (27) and for agricultural crops (Biftu \& Gan, 2001) (28):

$$
\begin{gathered}
L A I=N D V I \cdot 1.71+0.48 \\
L A I=-2.5 \cdot \ln (1.2-2 \cdot N D V I)
\end{gathered}
$$

Specified in that way time behavior of LAI is presented at Fig. 14. Here sudden changes correspond to time intervals of plant mowing.

In initial versions of the model the fraction B was calculated as follow

$$
B=1-\exp (-p \cdot L A I)
$$

Here $p$ is empirical coefficient that was adjusted by comparing modeled magnitudes of $T_{f}$, $T_{g}$, and $T_{s}$ with satellite-derived values of $T_{a}, T_{s g}$, and $T_{\text {s.eff }}$ using LAI estimates determined from both satellite and ground data. Numerical experiments were carried out under three scenarios of estimating $L A I$ and $B: 1$ ) values of $B$ were calculated by (29) using $L A I$ determined by ground observation data on phenological stage changes and plant heights for different land-use; 2) values of $B$ were also calculated by (29) using satellite- 


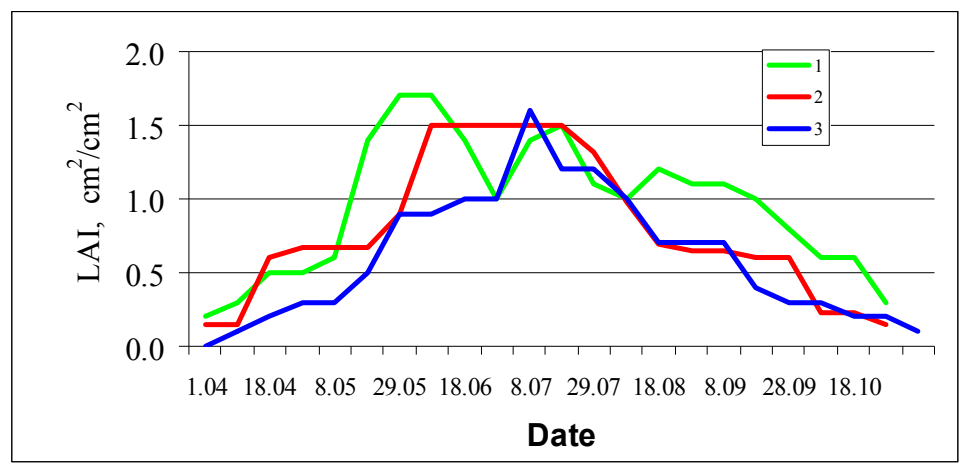

Fig. 14. Temporal behavior of LAI for vegetation season 2004 built by data of AVHRR/3 (1), MODIS (3) and by ground observation data at water balance station Nizhnedevitsk for perennial grasses $(1,2)$ and without allocation of cultures (3)

derived $L A I ; 3)$ estimates of $B$ and $L A I$ were generated from satellite data. Values of $T_{a}$ and $T_{f}$ under these scenarios are close to each other: for the most of observation times their differences do not exceed 2.5 and $3.5^{\circ} \mathrm{C}$ respectively (i.e. they are close to RMSE for satellitederived $\left.T_{a}\right)$. These results are confirmed by rather high (0.65-0.75 at different seasons) $T_{f}$ and $T_{a}$ correlation coefficient. Similar results were also obtained when comparing $T_{s}$ with $T_{s . e f f}$ and $T_{s g}$ with $T_{g}$ under all the scenarios. Examples of comparing AVHRR-derived and ground-based estimates of $B$ for perennial grasses are presented in Fig. 15.

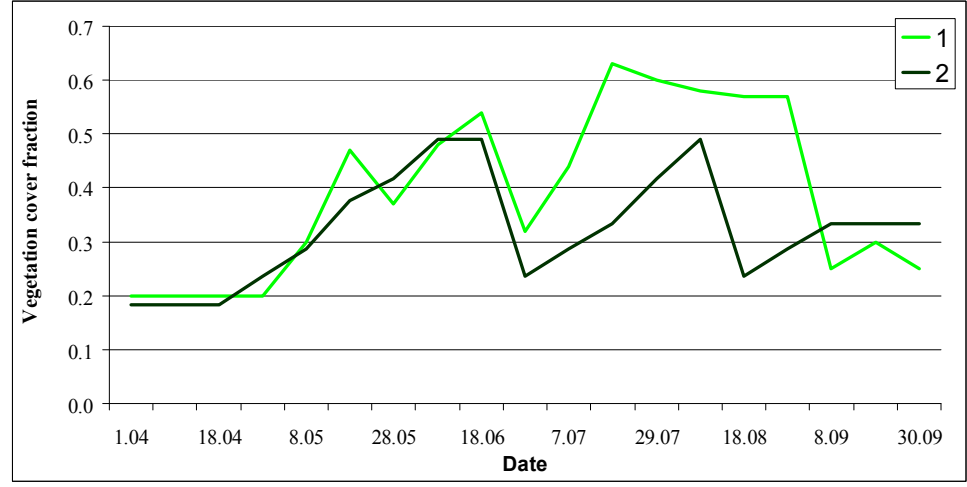

Fig. 15. Comparing AVHRR-derived (1) and ground-based estimates (2) of vegetation cover fraction $B$ for perennial grasses at the station Kursk for vegetation season 1999

Described results gave impetus to research possibility of direct use of satellite-based estimates of vegetation cover and LSTs in the model. High desirability of such use while model simulating water and heat balance components for vast territories is due to the necessity of distributed estimates of the land surface characteristics, especially under the lack of ground-based observation data. To assimilate satellite-based estimates of vegetation and meteorological characteristics the updating of the SVAT model has been performed including: 
1. Replacing the ground point-wise estimates of the model parameters $L A I$ and $B$ by their AVHRR- or MODIS-based analogues. The efficiency of such approach has been proved through comparisons: between satellite-derived and ground-based data on LAI and $B$ behavior during vegetation season; between satellite-derived, modeled, and insitu measured temperatures; between modeled and actual values of evapotranspiration Ev (Fig. 16) and of soil water content $W$ for one-meter soil layer (Fig. 17). The

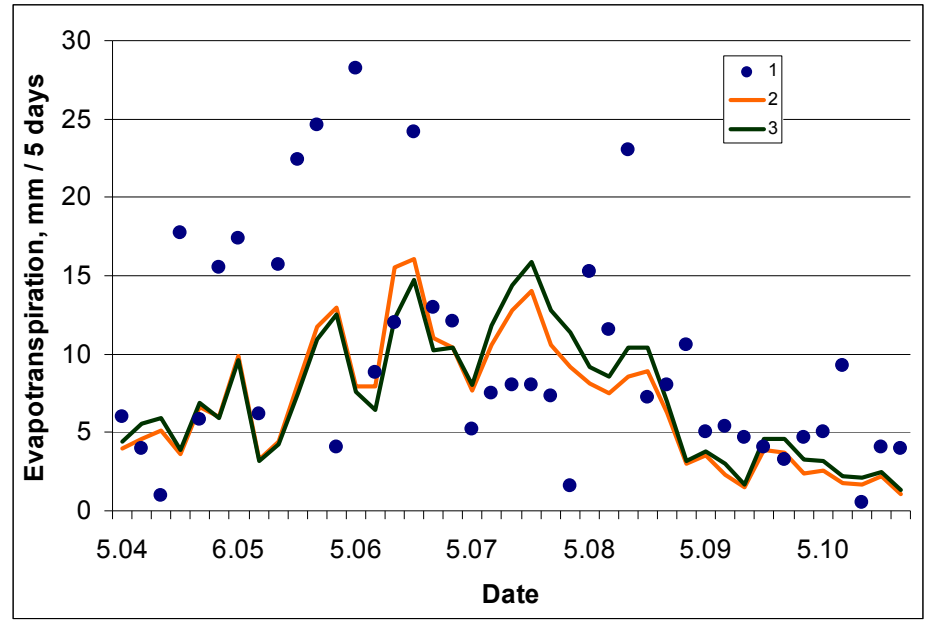

Fig. 16. Evapotranspiration Ev for vegetation season 2008 measured on grassland at water balance station Nizhnedevitsk (1), modeled using AVHRR-derived LAI for perennial grasses (3) and MODIS-derived LAI (2)
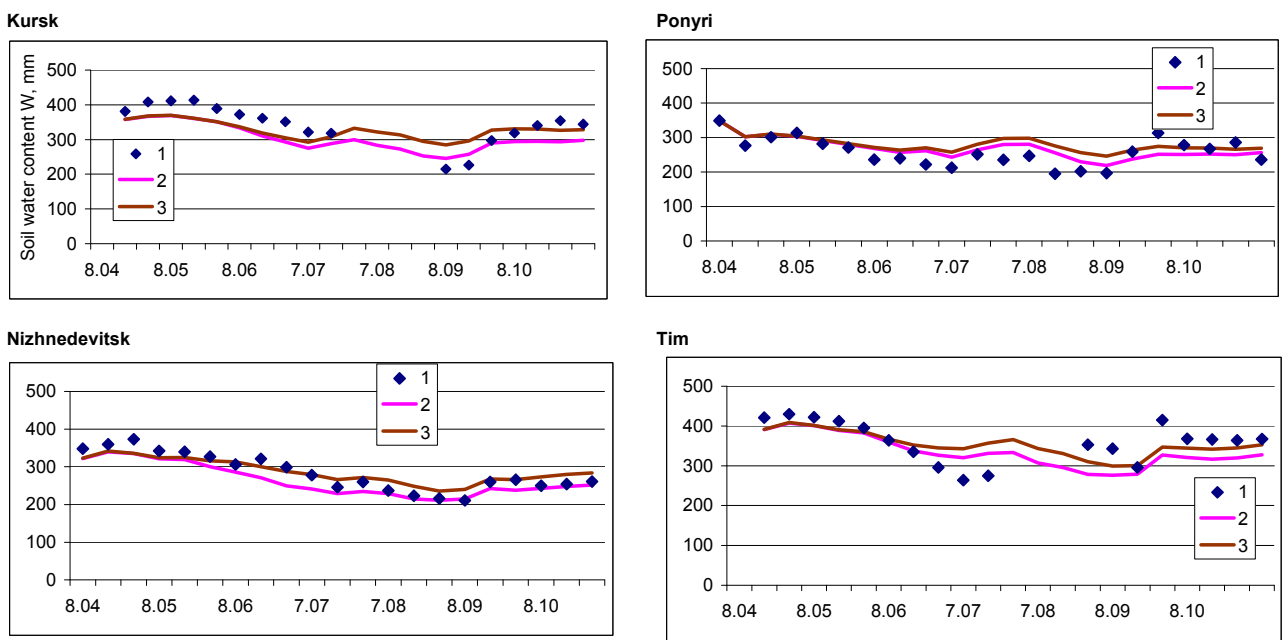

Fig. 17. Soil water content: ground measured for corn at four agricultural meteorological stations (1), modeled using AVHRR-derived LAI and B for corn (2) and MODIS-derived LAI (3) for vegetation season 2008. 
discrepancies between $T_{a}, T_{s}, T_{\text {s.eff }}$ and $T_{f}, T_{g}, T_{s}$ as well as between $T_{l s}$ and $T_{s}$ and ground-measured ones do not exceed standard errors of satellite-derived estimates $T_{a}$, $T_{\text {sg }}$ and $T_{\text {s.eff }}$ respectively while the modeled and measured values of $E v$ and $W$ are found close to each other within a standard error of their estimation.

2. Entering the AVHRR- or MODIS-based LST estimates as the input SVAT model variables instead of their standard ground-based estimates if the time-matching of satellite and ground-based observations takes place. The SEVIRI-derived $T_{l s}$ estimates can also play the same role. Permissibility of such replacement has been verified while comparing remote sensed, modeled and ground-based temperatures as well as calculated and measured values of $W$ and Ev (Fig. 18) The SEVIRI-based $T_{l s}$ estimates are found to be very informative and useful due to their high (up to $15 \mathrm{~min}$ ) temporal resolution.

3. Inputting AVHRR- and MODIS-derived LAI and B, AVHRR-, MODIS-, and SEVIRIbased LSTs in each grid cell of the model in order to account for the space variability of vegetation cover parameters and meteorological characteristics. Ground-based data on precipitation, air temperature and humidity prepared by Inverse Distance Squared (IDS) interpolation method are also inserted into the model in each grid node. The calculations of vertical water and heat fluxes, soil water and heat contents and other water and heat balance components for above region of interest have been carried out using the described updated SVAT model and the fields of AVHRR/3- or MODIS-derived LAI and $B$ estimates together with AVHRR/3- or MODIS- or SEVIRI-derived $T_{l s}$ retrievals for 1999-2010 vegetation seasons. Fig.19 shows the results of calculation of latent heat flux and soil water content at the same date of 2010 as shown in Fig. 7. The acceptable accuracy levels for above values assessment have been achieved under all scenarios of parameter and input model variable specification using satellite- and ground-based data.

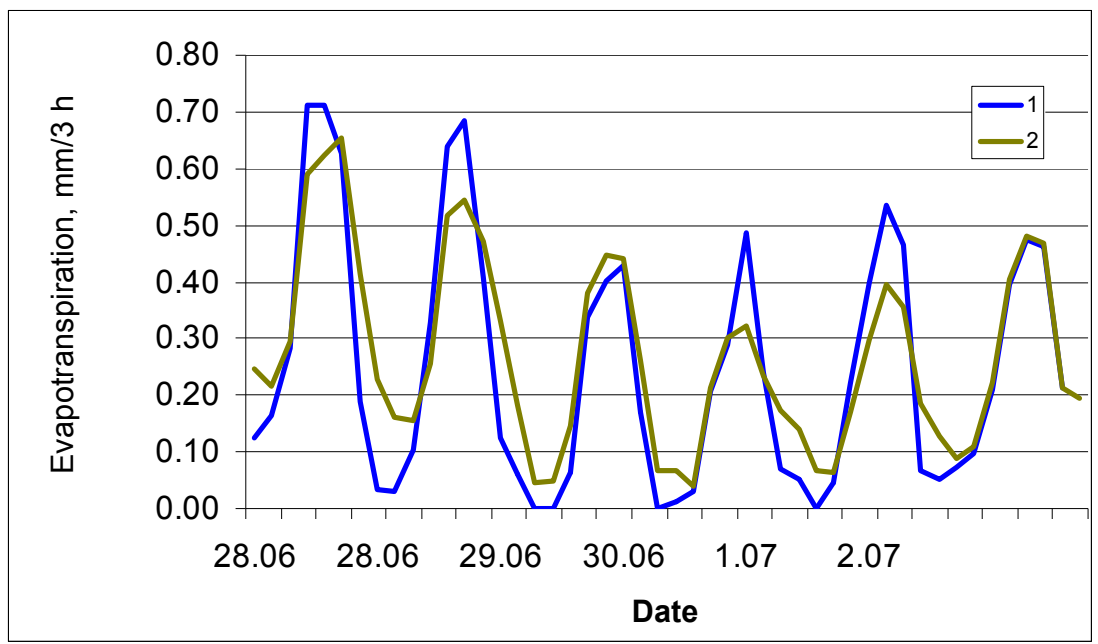

Fig. 18. Three-hour values of evapotranspiration modeled using SEVIRI-derived data (1) and three-hour observation data at the agricultural meteorological station Livny (2) on 28.06.-03.07.2009 


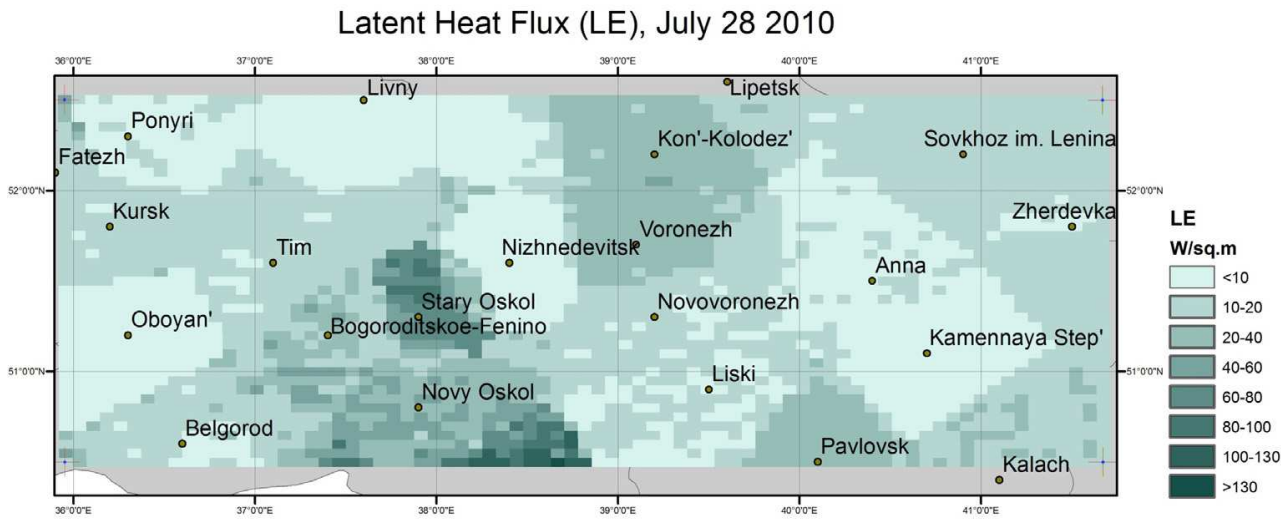

Soil Water Content (SWC), July 282010

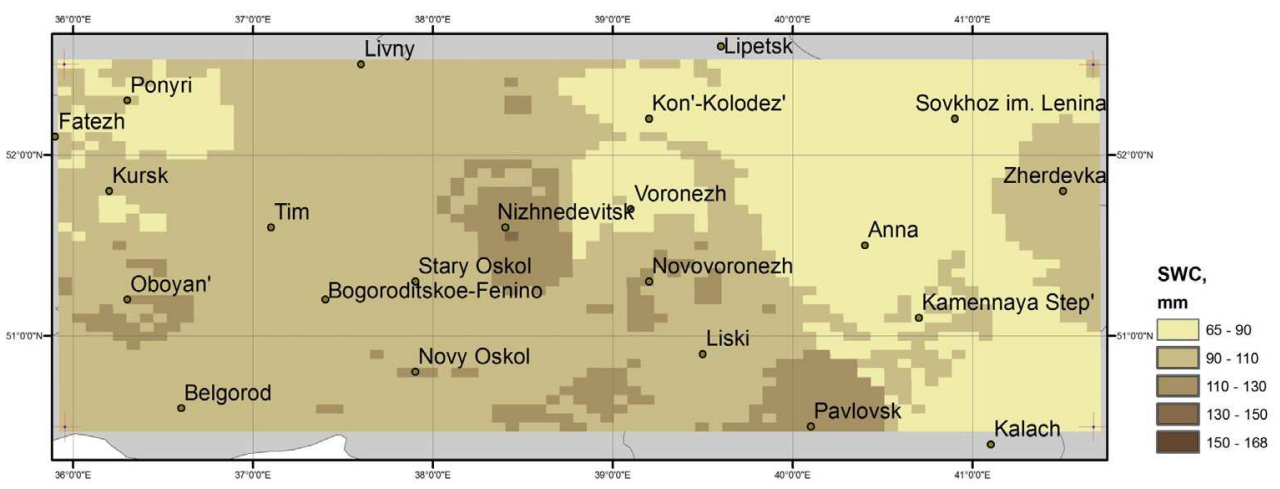

Fig. 19. Calculated latent heat flux and soil water content distributed over the study region

As follows from the above, the presented approach can be used for vast territories under the lack or absence of ground observations. The most promising in this case is the utilization of SEVIRI data due to their frequent occurrence.

\subsection{Satellite based modeling of snow cover}

The calibrated snow model (14) - (22) was applied to calculate snow cover characteristics in each $0.01^{\circ}$ pixel of the spatial grid within the study areas. The meteorological data interpolated from the available meteorological stations to each pixel by the IDS method were used as the input to the snow cover models. In pixels where MODIS data were available the simulated land surface temperature and albedo were replaced by corresponding satellite-derived variables. Fields of snow cover characteristics based on satellite observations and the snow pack model were generated for the study area for the time period from January 1st to May 31th of the years 2002 - 2005. The initial snow cover distribution in the model was assigned following AMSR-derived SWE data on 1 January for all pixels. For the pixels where the initial SWE values were unavailable because of the lack of 
coverage or for some other reasons, these values were interpolated from neighboring pixels by the IDS interpolation method.

Maps of the simulated distributions of these snow characteristics were compared with the corresponding satellite maps. The simulated changes of SCA were appeared to be in satisfactory correspondence with the satellite-derived SCA. As an example of this correspondence, simulated and satellite-derived dynamics SCA are shown in Fig. 20 for several sub-regions adjoining the meteorological stations of the study area.

2. Gotnya

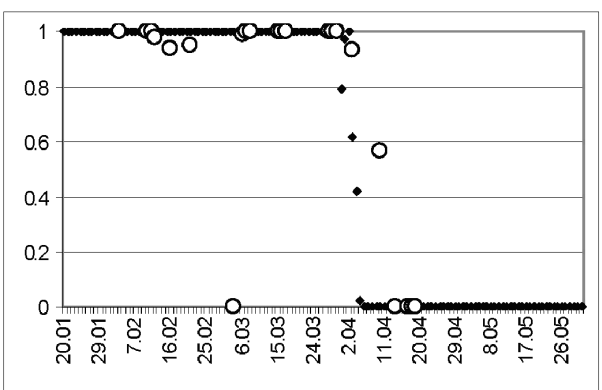

27. Yelatma

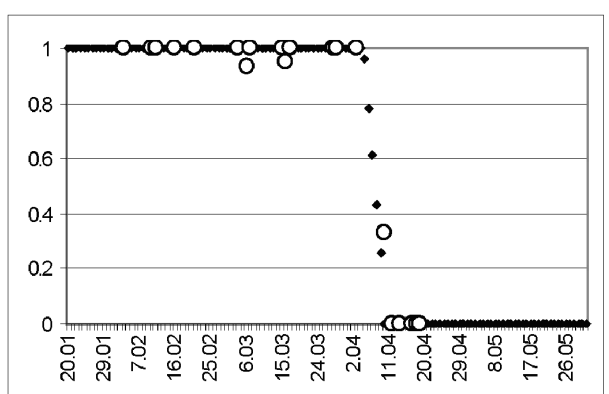

18. Tula

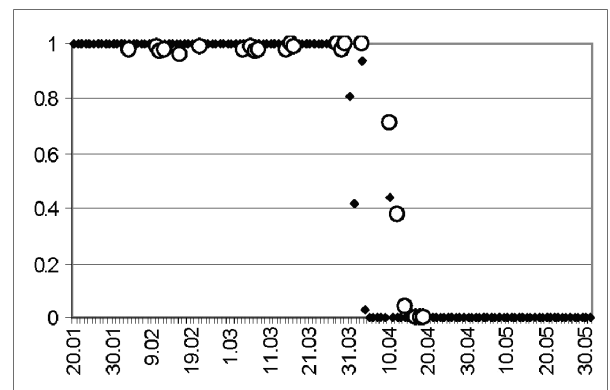

31. Lipetsk

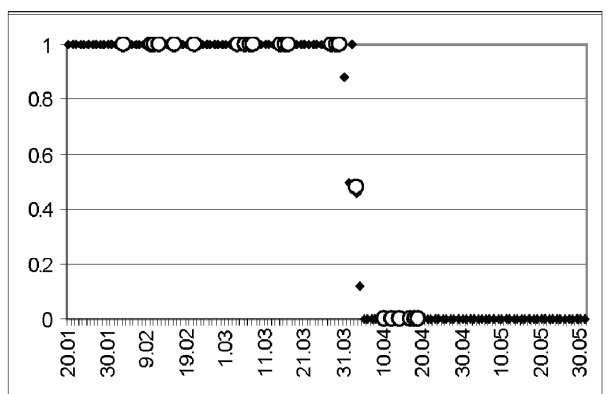

Fig. 20. Simulated (solid dots) and MODIS-derived (circles) dynamics of SCA for some polygons within the study area (winter-spring season of 2004)

However, the simulated maps of SWE substantially differ from the corresponding AMSRderived SWE maps as it is illustrated by Fig. 21. We assume that this difference is resulted from by the fact that the accuracy of the SWE estimated from the radiometric satellite measurements noticeably decreases during melt period when snowpack is saturated by melted water so the AMSR-derived SWE maps may not adequately represent the real SWE distribution for this period of the year. 
Mar 25
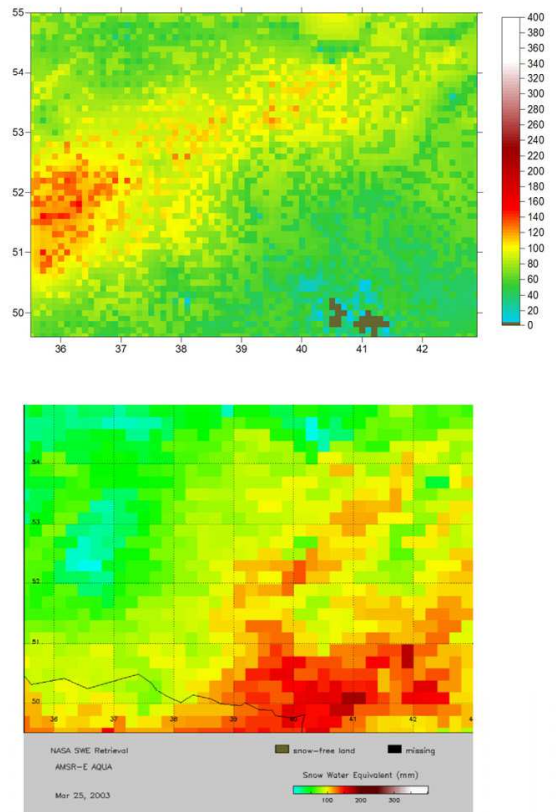

Mar 26
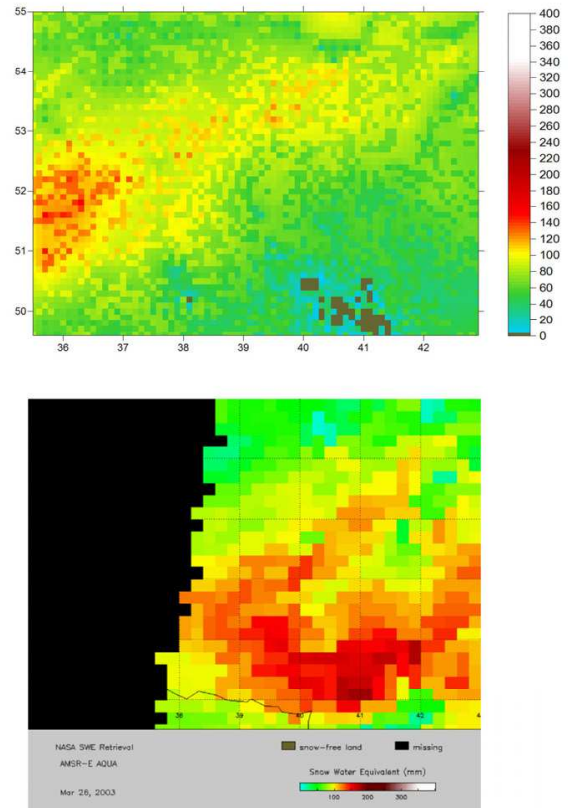

Fig. 21. Simulated (upper raw) and AMSR-derived (lower raw) distribution of SWE (mm) on 25-26 March, 2003.

\section{Conclusion}

The paper highlights the importance of satellite remote sensing data used in conjunction with a land surface model in describing water and heat regimes of vast agricultural regions. Accuracy and robustness of the corresponding quantified assessments by LSM is strongly restricted by insufficiency, both in space and time, of ground observations of highly heterogenic soil, vegetation and snow characteristics, soil temperature, etc., which can be used as the model parameters or input variables, as well as for calibration and validation of the model. Satellite remote sensing is not only an additional source of land surface data allowing substitution of the missed ground observations into the model, but, for majority of regions, it is a unique data source. From the other side, in spite of the diversity of satellite data on land surface characteristics and technologies of the data thematic processing, opportunity of using these data in LSMs is often problematic because of many reasons, e.g. irregularity of data, uncertain data accuracy, etc.

Moreover, there is no general approach allowing reliable choice of appropriate satellite data and/or processing technique; this choice depends on both specific features of the region of interest and the used model. In this study, we tried, firstly, to demonstrate opportunities of utilizing land-surface/snow remote sensing products obtained from the different satellites (NOAA, EOS Terra and Aqua, METEOSAT-9) and sensors (SEVIRI, AMSR-E, AVHRR, MODIS) in the developed LSM. Secondly, we analyzed sensitivity of the simulation results to different satellite remote sensing data. It is important that most of the used products were 
derived by the originally developed processing techniques, especially new technique for processing SEVIRI measurement and the technology based on synergy of optical and microwave snow products. Other main emphasis of the study is to develop a new physically based distributed Remote Sensing Based Land Surface Model (RSBLSM). The model is aimed to simulation of vertical water-and-heat transfer and, importantly, it takes into account hydrothermal processes in the "frozen soil-snow-atmosphere" system. These processes are critical for cold region agriculture, as they define crop development in early spring before the vegetation season beginning.

The obtained results allow us to conclude that utilization of the differently derived satellitebased estimates in the developed physically based model, intensively calibrated and validated against the available ground observations, provides an opportunity for reproducing spatial fields of evapotranspiration, soil moisture and temperature at different soil depths, temperature of soil/vegetation surfaces, snow and other water and heat characteristics for the vast agricultural region.

\section{Acknowledgment}

We thank E.Volkova, A.Kukharsky, S.Uspensky, V.Solovjev from SRC "Planeta" for their participation in the development of satellite data processing methods, as well as M.Alexadrovich from Water Problem Institute of RAS for technical assistance in modeling and data processing. The presented study was carried out under support of the Russian Foundation of Basic Researches (grant № 10-05-00807).

\section{References}

Armstrong, R. L., Brodzik, M. J. (2005) Northern Hemisphere EASE-Grid Weekly Snow Cover and Sea Ice Extent Version 3. Digital media, http://nsidc.org/data/nsidc0046.html, National Snow and Ice Data Center, Boulder, Colorado, USA.

Becker F, Li, Z.-L. (1995) Surface temperature and emissivity at various scales: definition, measurement and related problems. Rem. Sens. Rev.,Vol. 12, pp. 225-253.

Biospheric Aspects of the Hydrological Cycle (BAHC). (1993) Report № 27, 103 p. Ed. by BAHC Core Project Office, Institut für Meteorologie, Freie Universitat Berlin, Germany.

Biftu, G.F., Gan, T.Y. (2001) Semi-distributed, physically based, hydrologic modeling of the Paddle River basin, Alberta, using remotely sensed data. J. Hydrol., Vol. 244, pp. 137-156.

Brodzik, M. J., Armstrong, R., Savoie, M. (2007) Global EASE-Grid 8-day Blended SSM/I and MODIS Snow Cover. Digital media.

http://nsidc.org/data/docs/daac/nsidc0321_8day_ssmi_modis_blend/index.html, National Snow and Ice Data Center, Boulder, Colorado, USA.

Brooks, R.H., Corey, A.T. (1964) Hydraulic properties of porous media. Hydrol. Pap. Colorado State Univ. № 3. 27 p.

Brubaker, K. L., Pinker, R. T., Deviatova, E. (2005) Evaluation and Comparison of MODIS and IMS Snow-Cover Estimates for the Continental United States Using Station Data. J. Hydrometeor., Vol. 6, pp. 1002-1017. doi: 10.1175/JHM447.1 
Clupp, R.B., Hornberger, G.M. (1978) Empirical equations for some hydraulic properties. Water Resources Research, Vol. 14, № 4, pp. 601-604.

Collatz, G.J., Ball. J.T., Grivet, C., Berry, J.A. (1991) Physiological and environmental regulation of stomatal conductance, photosynthesis and transpiration: a model that includes a laminar boundary layer. Agricultural and Forest Meteorology, Vol. 54, pp. 107-136.

Dai, Y., et al. (2003) The Common Land Model (CLM) version 1.0. Bull. Am. Meteorol. Soc., Vol. 84, pp. 1013- 1023.

de Wildt, M. D., Gabriela, S., Gruen, A. (2007) Operational snow mapping using multitemporal Meteosat SEVIRI imagery. Remote Sensing of Environment, Vol. 109, pp. 29-41.

Deardorff ,J.W. (1978) Efficient prediction of ground surface temperature and moisture with inclusion of a layer of vegetation. Journal of Geophysical Research, Vol. 83, pp. 18891903.

Desborough, C.E., Pitman, A.J. (1998) The BASE land surface model. Global and Planetary Change, Vol. 19, pp. 3-18.

Dickinson, R.E., Henderson-Sellers, A., Kennedy, P.J., Wilson, M.F. (1986) Biosphere Atmosphere Transfer Scheme (BATS) for the NCAR Community Climate Model, NCAR Tech. Note, TN-275 + STR, 69 pp.

Faysash, A., Smith, E.A. (2000) Simultaneous Retrieval of Diurnal to Seasonal Surface Temperatures and Emissivities over SGP ARM-CART Site Using GOES Split Window. J. Appl. Meteor., Vol. 39, pp. 971-982.

Foster, J.L., Hall, D. K., Eylander, J.B., Riggs, G.A., Nghiem, S.V., Tedesco, M., Kim, E., Montesano, P.M., Kelly, R. E.J., Casey, K.A., Choudhury, B. (2011) A blended global snow product using visible, passive microwave and scatterometer satellite data. International Journal of Remote Sensing, Vol. 32, pp. 1371-1395.

Gelfan, A. N., Pomeroy, J. W., Kuchment, L.S. (2004) Modelling forest cover influences on snow accumulation, sublimation, and melt. J. Hydrometeorology, Vol. 5, No. 5, pp. 785-803.

Gelfan, A. N. (2006) Physically based model of heat and water transfer in frozen soil and its parametrization by basic soil data. In: Predictions in Ungauged Basins: Promises and Progress. Proceedings of symposium S7 held during the Seventh IAHS Scientific Assembly at Foz do Iguazu, Brazil, April 2005, Eds: M. Sivapalan,. IAHS Publ., Vol. 303, pp. 293304.

Global Water Security - an engineering perspective. Report of the The Royal Academy of Engineering, Publ. by The Royal Academy of Engineering, London, UK, April 2010.

Good, E. (2009) Blending in situ and satellite data for monitoring land air temperatures. Proc. of the 2009 Eumetsat Meteorol. Sat. Conf, Bath, UK, 21 - 25 September 2009, 5 p.

Grody, N.C., Basist, A.N. (1996) Global identification of snow cover using SSM/I Measurements. IEEE Trans. Geosci. Remote Sens., Vol. 34, N 1, pp. 237-249.

Gusev, E. M., Nasonova, O.N. (2002) The simulation of heat and water exchange at the landatmosphere interface for the boreal grassland by the land-surface model SWAP. Hydrol. Processes, Vol. 16, pp. 1893-1919.

Hall, D.K., Riggs, G., Salomonson, V., DiGirolamo, N.E., Bayr, K.J. (2002) MODIS snow cover products. Remote Sensing of Environment, V. 83, pp. 181-194. 
Hall, D.K, Riggs, G.A. (2007) Accuracy assessment of the MODIS snow-cover products. Hydrological Processes, Vol. 21, pp. 1534-1547.

Helfrich, S.R., McNamara, D., Ramsay, B.H., Baldwin, T., Kasheta, T. (2007) Enhancements to, and forthcoming developments in the Interactive Multisensor Snow and Ice Mapping System (IMS). Hydrological Processes, Vol. 21, pp. 1576-1586.

Henderson-Sellers, A, Pitman, A.J., Love, P.K., Irannejad, P., Chen, T. (1995) The project for intercomparison of land surface parameterization schemes (PILPS) phases 2 and 3. Bulletin of the American Meteorological Society, Vol. 76, pp. 489-503.

Justice, C. O., Vermote, E., Townshend, J. R. G., et al. (1998) The Moderate Resolution Imaging Spectroradiometer (MODIS): land remote sensing for global change research. IEEE Trans. Geosci. Remote Sens., Vol. 36, pp. 228-1249.

Kelly, R. E., Chang, A. T., Tsang, L., Foster, J.L. (2003) A prototype AMSR-E global snow area and snow depth algorithm. IEEE Transactions on Geoscience and Remote Sensing, Vol. 1, pp. 230-242.

Kuchment, L.S., Motovilov, Yu., G., Startseva, Z.P. (1990) Modeling of moisture transport in the soil-vegetation-surface boundary layer system for hydrological problems. Water Resources, Vol. 16, N 2, pp. 121-128. (Translated from Russian, Vodnye Resursy (1989), N 2, pp.32-39, Plenum Publishing Corporation, Consultants Bureau, New York, USA).

Kuchment, L.S., Startseva, Z.P. (1991) Sensitivity of evapotranspiration and soil moisture in wheat fields to changes in climate and direct effects of carbon dioxide. Hydrol. Sci. J., Vol. 36, N 6, pp. 631-643.

Kuchment, L. S., Gelfan, A.N. (1996) The determination of the snowmelt rate and the meltwater outflow from a snowpack for modeling river runoff generation. $J$. Hydrology, Vol.179, pp. 23-36.

Kuchment, L.S., Demidov, V.N., Startseva, Z.P. (2006) Coupled modeling of the hydrological and carbon cycles in the soil-vegetation-atmosphere system. J. Hydrology, Vol.323, pp.4-21

Kuchment, L.S., Romanov, P., Gelfan, A.N., Demidov, V.N. (2010) Use of satellite-derived data for characterization of snow cover and simulation of snowmelt runoff through a distributed physicall basedmodel of runoff generation Hydrol. Earth Syst. Sci., Vol. 14, pp. 339-350.

Lokupitiya, E., et al. (2009) Incorporation of crop phenology in Simple Biosphere Model (SiBcrop) to improve land-atmosphere carbon exchanges from croplands. Biogeosciences, Vol.6, pp.969-986.

Manabe, S. (1969) Climate and the ocean circulation. The atmospheric circulation and hydrology of the Earths surface. Mon.Wea. Rev., Vol. 97, pp. 739-774.

Mauser, W., Schädlich, S. (1998) Modelling the spatial distribution of evapotranspiration on different scales using remote sensing. J. Hydrol., Vol. 212-213, pp. 250-267.

Milly, P.C.D., Shmakin, A.B. (2002) Global modeling of land water and energy balances. Part I: the Land Dynamics (LaD) model. Journal of Hydrometeorology, Vol. 3, pp. 283-299.

Muzylev, E.L., Uspensky, A.B., Volkova, E.V., Startseva, Z.P. (2002) Simulation of hydrological cycle of river basins using synchronous high resolution satellite data. Russian Meteorology and Hydrology, N 5, pp. 52-63. 
Muzylev, E.L., Uspensky, A.B., Volkova, E.V., Startseva, Z.P. (2005) Using satellite information for modeling heat and moisture transfer in river watersheds. Earth Research from Space, N 4, pp. 35-44. (In Russ.)

Muzylev, E., Uspensky, A., Startseva, Z., Volkova, E. (2006) Modeling vertical heat and water fluxes from river basin area with AVHRR/NOAA-based information on land surface characteristics. Proc. of the 7th International Conference on Hydroinformatics, Nice, France, 4-8 September 2006. Ed. P.Gourbesville, J.Cunge, V.Guinot, S.-Y.Liong, Vol. 2, pp. 1163-1170, Research Publishing, Chennai, India.

Muzylev, E.L., Uspenskii, A.B., Startseva, Z.P., Volkova, E.V., Kukharskii, A.V. (2010) Modeling water and heat balance components for the river basin using remote sensing data on underlying surface characteristics. Russian Meteorology and Hydrology, Vol. 35, N 3, pp. 225-235, DOI: 10.3103/S1068373910030106

NOAA KLM User's Guide. (2005) http://www.ncdc.noaa.gov/oa/pod-guide/ncdc/docs/klm/html/ c1/sec1-2.htm.

Oleson, K.W., Niu, G.-Y., Yang, Z.-L., Lawrence, D. M., Thornton, P. E., Lawrence, P. J., Stöckli, R., Dickinson, R. E., Bonan, G. B., Levis, S., Dai, A., Qian, T. (2008) Improvements to the Community Land Model and their impact on the hydrological cycle. J. Geophys. Res., Vol. 113, G 01021, doi:10.1029/2007JG000563.

Overgaard, J., Rosbjerg, D., Butts, M. B. (2006) Land-surface modelling in hydrological perspective - a review. Biogeosciences, Vol. 3, pp. 229-241.

Pitman, A.J. (2003) The evolution of, and revolution in, land surface schemes designed for climate models. Int. J. Climatol., Vol. 3, pp. 479-510.

PUM LST (Product User Manual. Land Surface Temperature) (2008) SAF/LAND/IM/ PUM_LST/2.1, 49p.

Romanov, P., Gutman. G., Csiszar, I. (2000) Automated monitoring of snow over North America with multispectral satellite data. Journal of Applied Meteorology, Vol. 39, pp. 1866-1880.

Romanov, P. (2011) Satellite-Derived Information on Snow Cover for Agriculture Applications in Ukraine, in Use of Satellite and In-Situ Data to Improve Sustainability. NATO Science for Peace and Security Series C: Environmental Security. Part 2, pp.81-91, DOI: 10.1007/978-90-481-9618-0_9

Rutter, N. et al. (2009), Evaluation of forest snow processes models (SnowMIP2), J. Geophys. Res., 114, D06111, doi:10.1029/2008JD011063

Schmetz, J., Pili, P., Tjemkes, S., Just, D. et al., (2002) An introduction to Meteosat Second Generation (MSG). Bull. Amer. Meteor. Soc., Vol. 83, pp. 977-992.

Schultz, K., Franks, S., Beven, K. (1998) TOPUP - A TOPMODEL based SVAT model to calculate evaporative fluxes between the land surface and the atmosphere, Version 1.1, Program documentation, Department of Environmental Science, Lancaster University, UK.

Sellers, P.J, Mintz, Y., Sud, Y.C., Dalcher, A. (1986) A Simple Biosphere model (SiB) for use within general circulation models. Journal of the Atmospheric Sciences, Vol. 43, pp. 505-531.

Sellers, P.J., Berry, J.A., Collatz, G.J., Field, C.B., Hall, F.G. (1992) Canopy reflectance, photosynthesis and transpiration. III. A reanalysis using improved leaf models and a new canopy integration scheme. Remote Sensing of the Environment, Vol. 42, pp. 187-216. 
Sellers, P. J., Dickinson, R. E., Randall, D. A., Betts, A. K., Hall, F. G., Berry, J. A., Collatz, G. J., Denning, A. S., Mooney, H. A., Nobre, C. A., Sato, N., Field, C. B., HendersonSellers, A. (1997) Modeling the exchanges of energy, water, and carbon between continents and the atmosphere. Science, Vol. 275, pp. 502-509.

Simic, A., Fernandes, R., Brown, R., Romanov, P., Park, W. (2004). Validation of VEGETATION, MODIS, and GOES C SSM/I snow-cover products over Canada based on surface snow depth observations. Hydrological Processes, Vol. 18, No. 6, pp. 1089-1104.

Snyder, W.C., Wan, Z., Zhang, Y., Feng, Y.-Z. (1998) Classification-based emissivity for land surface temperature measurement from space. Int. J. Rem. Sens., Vol. 19, No. 14, pp. 2753-2774.

Solovjev, V.I., Uspensky, S.A. (2009) Monitoring of land surface temperatures based on second generation geostationary meteorological satellites, Earth Studies from Space, No. 3, pp.17-25, (in Russian).

Solovjev, V.I., Uspensky, A.B., Uspensky, S.A. (2010) Derivation of land surface temperature using measurements of IR radiances from geostationary meteorological satellites, Russian Meteorology and Hydrology, Vol. 35, No. 3, pp. 159-167, DOI 10.3103/ S1068373910030015.

Uspensky, S., Solovjiev, V., Uspensky, A.,(2009) Monitoring of land surface temperatures based on SEVIRI/METEOSAT-9 measurements. Proceedings of 2009 EUMETSAT Meteorological Satellite Conference, 2009, EUMETSAT, pp 55-60.

Uspensky, S., Uspensky, A., Rublev, A. (2011) Land surface air temperature retrieval capabilities with geostationary meteorological satellite data. Proc. "Intern. Symp. on Atmospheric Radiation and Dynamics", St.Petersburg, June 21-24, 2011,pp. 37-38.

van Genuchten, M.Th. (1980) A closed form equation for predicting the hydraulic conductivity of unsaturated soils. Soil Sci. Soc. Am. J., No. 44, pp.892-898.

Volkova, E.V., Uspenskii, A.B. (2007). Detection of clouds and identification of their parameters from the satellite data in the daytime. Russian Meteorology and Hydrology. Vol. 32, No. 12, pp. 723-732, DOI: 10.3103/S1068373907120011.

Walker, A.E., Goodison, B.E. (1993) Discrimination of a wet snow cover using passive microwave satellite data. Annals of Glaciology, Vol. 17, pp. 301-311

Wan, Z., Dozier, J. (1996) A generalised split-window algorithm for retrieving land surface temperature from space. IEEE Trans. Geosci. Rem. Sens., Vol. 34, No. 4, pp. 892-905.

Wood, E.F, Lettenmaier, D.P, Zartarian, V.G. (1992) A land-surface hydrology parameterization with subgrid variability for general circulation models. Journal of Geophysical Research Vol. 97, pp. 2717-2728.

Yang, Z.-L. (2004) Modeling land surface processes in short term weather and climate studies, In: Observation, Theory and Modeling of Atmospheric Variability, Ed. X. Zhu, X. Li, M. Cai, S. Zhou, Y. Zhu, F.-F. Jin, X. Zou, and M. Zhang, pp. 288-313, World Scientific Series on Meteorology of East Asia, World Scientific, New Jersey. 


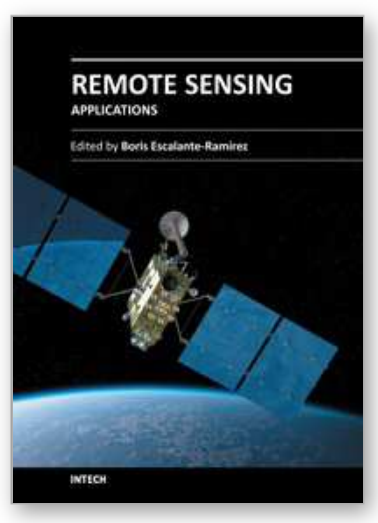

\author{
Remote Sensing - Applications \\ Edited by Dr. Boris Escalante
}

ISBN 978-953-51-0651-7

Hard cover, 516 pages

Publisher InTech

Published online 13, June, 2012

Published in print edition June, 2012

Nowadays it is hard to find areas of human activity and development that have not profited from or contributed to remote sensing. Natural, physical and social activities find in remote sensing a common ground for interaction and development. This book intends to show the reader how remote sensing impacts other areas of science, technology, and human activity, by displaying a selected number of high quality contributions dealing with different remote sensing applications.

\title{
How to reference
}

In order to correctly reference this scholarly work, feel free to copy and paste the following:

A. Gelfan, E. Muzylev, A. Uspensky, Z. Startseva and P. Romanov (2012). Remote Sensing Based Modeling of Water and Heat Regimes in a Vast Agricultural Region, Remote Sensing - Applications, Dr. Boris Escalante (Ed.), ISBN: 978-953-51-0651-7, InTech, Available from: http://www.intechopen.com/books/remote-sensingapplications/remote-sensing-based-modeling-of-water-and-heat-regimes-in-a-vast-agricultural-region

\section{INTECH}

open science | open minds

\section{InTech Europe}

University Campus STeP Ri

Slavka Krautzeka 83/A

51000 Rijeka, Croatia

Phone: +385 (51) 770447

Fax: +385 (51) 686166

www.intechopen.com

\section{InTech China}

Unit 405, Office Block, Hotel Equatorial Shanghai

No.65, Yan An Road (West), Shanghai, 200040, China

中国上海市延安西路65号上海国际贵都大饭店办公楼 405 单元

Phone: +86-21-62489820

Fax: $+86-21-62489821$ 
(C) 2012 The Author(s). Licensee IntechOpen. This is an open access article distributed under the terms of the Creative Commons Attribution 3.0 License, which permits unrestricted use, distribution, and reproduction in any medium, provided the original work is properly cited. 